\title{
Impact Attenuation Performance of Surfaces Installed Under Playground Equipment
}

Bal M. Mahajan

William B. Beine

Product Safety Technology Division Center for Consumer Product Technology National Bureau of Standards

February 1979

Report To:

ner Product Safety Commission

$-Q C \longrightarrow$ Vestbard Avenue 100 Ja, Maryland 20016

.456

79-1707 


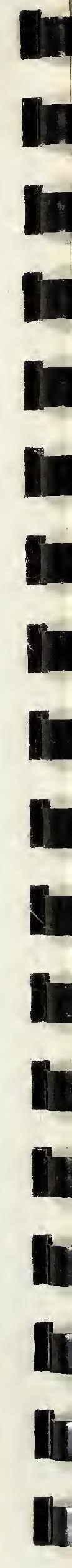




\section{IMPACT ATTENUATION PERFORMANCE OF SURFACES INSTALLED UNDER PLAYGROUND EQUIPMENT}

Bal M. Mahajan

William B. Beine

Product Safety Technology Division

Center for Consumer Product Technology

National Bureau of Standards

February 1979

Report To:

Consumer Product Safety Commission

5401 Westbard Avenue

Bethesda, Maryland 20016

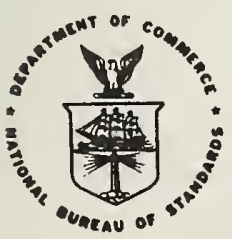

U.S. DEPARTMENT OF COMMERCE, Juanita M. Kreps, Secretary Jordan J. Baruch, Assistant Secretary for Science and Technology NATIONAL BUREAU OF STANDARDS, Ernest Ambler, Director 



\section{ABSTRACT}

This report describes a test method and a suggested criterion for evaluating the impact attenuation performance of playground surfacing materials intended to protect against head injury due to falls. Several types of surfacing materials have been tested and the results are included. These results indicate that some surfacing materials impart peak accelerations below this criterion for fall distances up to 10 feet while others exceed the criterion for relatiavely short fall distances. 
INTRODUCTION ............................

Purpose and Scope ................ . . 1

Background................... . .

HEAD INJURY AND TOLERANCES ............... 3

Head Injury . . . . . . . . . . . . . . 3

Tolerances................... 4

METHODOLOGY FOR TESTING SURFACES ............ 5

Test Method for Impact Attenuation. . . . . . . . . . 5

Impact Performance Criteria . . . . . . . . . . 5

TEST MATERIALS AND METHODS .............. . . 7

Material. . . . . . . . . . . . . 7

Specimen Size................ . . 7

Headform and Drop Apparatus . . . . . . . . . . 7

Instrumentation . . . . . . . . . . . . . . 8

Test Procedure................ . . 8

TEST RESULTS AND DISCUSSION. . . . . . . . . . 10

Presentation of Test Results. . . . . . . . . . 10

Discussion. . . . . . . . . . . . . . . . 11

CONCLUSIONS. . . . . . . . . . . . . . 13

REFERENCES 


\section{Purpose and Scope}

In 1975, the Consumer Product Safety Commission (CPSC) responded to a petition to develop a standard for Public Playground Equipment and selected the National Recreation and Park Association (NRPA) to develop such a standard. The NRPA thereupon formed a development panel, consisting of representatives from consumer, industry, and buyer/installer communities and called upon the Franklin Institute Research Laboratories for technical assistance. Approximately one year later, in April 1976, the NRPA submitted a proposed standard to the CPSC 1\%. The CPSC elected to revise that standard and sought technical assistance from the National Bureau of Standards (NBS). In November of 1977, a project was initiated at NBS for this purpose. A major task of this revision was to expand section 1514.10, "Surfaces Under Equipment," of the standard proposed by NRPA for probable publication as a separate Federal guideline for surfaces under equipment.

It was recognized that such a guideline should provide information on the impact attenuation performance of various surfaces and on such related factors as cost, durability, maintenance, resistance to weathering, sanitation, etc. The scope of the NBS effort was limited, however, to the impact attenuation performance of surfaces. The objectives of this effort were: 1) to develop a methodology for assessing the impact attenuation performance of surfaces in relation to head injury, and 2) to test surfaces commonly installed under playground equipment to determine which surfacing materials, if any, are capable of providing protection against head injury that might result when a child falls from equipment and impacts the surface. Due to the large variety of surfaces that can be installed under equipment, it would be impractical to test all such surfaces. Therefore, it was decided to test approximately ten commonly used surfacing materials, with some materials comprising two or three surfaces depending upon the depth of materials. The results of this task would provide CPSC with information useful in the formulation of a final version of the surfacing guideline.

\section{Background}

The majority ( 60 to $70 \%$ ) of public playground related injuries occur when users fall from equipment and impact the underlying surface $1 /, 2 /$ \& $3 /$. The surfaces beneath playground equipment that have been identified as "injury agents" in falls include asphalt, bare ground, concrete, gravel, sand and synthetic turf 2\%. Nearly half of the injuries resulting from equipment-to-surface falis are head injuries, ranging in severity from minor scalp bruises to skull fractures, concussions, and death. Head injuries resulting from such falls were the cause of death reported in two in-depth investigations; in both cases the underlying surface was asphalt $\underline{3} /$. 
Concern about child safety has prompted some sponsors and builders of playgrounds to install energy absorbing surfaces (such as rubber mats, synthetic turf, sand, wood mulch, etc.) beneath the equipment. However, information on the ability of surfacing materials to provide protection against head injury resulting from equipment-to-surface falls has not been readily available.

Roth and Burke 4/ and NRPA 1/ did test various surfacing materials for their ability to provide protection against head injury. These investigators used different criteria and procedures; hence, their results are not comparable. For example, Roth and Burke 4/ used two different hear simulators in their testing program and measured peak acceleration, whilo NRPA 1/ used still another type of head simulator and measured average acceleration. Relatively little has been done to develop a standard methodology (that is, criteria and test procedures) to assess the impact attenuation performance of surfaces in relation to head injury. 
HEAD INJURY AND TOLERANCES

Before discussing the development of a methodology to test surfaces for their ability to attenuate impact and reduce the risk of head injury due to falls, it is appropriate to consider first the types of head injuries that are likely to occur and the tolerance of the human head to impact.

\section{Head Injuries}

Head injuries can be grouped into three major categories according to site: scalp, skull and brain. Skull fractures and brain injuries are much more serious than injuries to the scalp; and consequently, they are the most important to be protected against. Although skull fracture can occur without brain injury 5/, Gurdjian 6/ reports that concussion (the most common brain injury) is associated with 80 percent of linear skull fractures. Impact-induced head injury is a complex subject, and a discussion of all aspects of such injuries is beyond the scope of this report. However, information on the various types of head injuries and their relative severity, head injury mechanisms, and the effects of important physical factors on resulting injury may be found in references 7 through 11. The following general description of immediate post-impact effects leading to skull and brain injuries are considered to be adequate for the purposes of this report.

When the head impacts a surface or when an object impacts the head, the head is subjected to an impulsive force. The magnitude, direction and duration of this impulsive force depends primarily upon the impact momentum, as well as on the mechanical properties of both the head and the object. Depending upon the contact area and the part of the head contacted during impact, the force generated may cause deformation of the skull, linear acceleration of the head, rotation of the head with respect to the neck and torso, or combinations of these.

Deformation of the skull may be expected when the contact area is sufficiently small, and this may contribute to skull fracture and concussion. These deformations are usually accompanied by head acceleration. Head acceleration without significant deformation is likely to result when the impulsive force is distributed over a large area. For example, this may occur when the head strikes a resilient surface or a surface consisting of loose material, such as sand.

Linear acceleration may cause relative motion of the brain with respect to the skull and changes in intracranial pressure. Either of these effects can lead to concussion. The severity of the resulting concussion will depend on the magnitude and duration of head acceleration.

Rotation of the head with respect to the neck and torso produces stretching of the neck ligaments, cervical cord, and brain stem. It may also produce relative motion between the skull and brain and changes in 
intracranial pressure. These consequences of head rotation can produce injury to the neck, cervical cord and brain.

\section{Tolerances}

The Wayne State University Tolerance Curve (WSU curve), shown in figure 1, was developed to predict human tolerance to linear fracture fin concussion $12 /$ and 13/. Based on experiments conducted on cadavers and animals, it is probably the best known device for predicting the tolerance of human head to impact. The WSU curve indicates that concussion is a function of both time and acceleration. When plotted on log-log paper, the WSU curve is a straight line for impulse durations between 2.5 and 50 milliseconds. Gadd 14/, using the slope of this straight line as the exponent of acceleration, devised the Severity Index (SI) as a measure of head tolerance to impact. Mathematically, SI is expressed as follows:

$$
S I=\int_{0}^{t} a^{2.5} d t
$$

where $a$ is the acceleration expressed in units of $g$, the value of acceleration due to gravity. A value of SI equal to 1000 was suggested by Gadd as the threshold for concussion.

In a recent study, Mohan, et. al. 15/ reported that a conservative estimate of head injury tolerance limits for head-first falls of children are 150-200 g's average acceleration for 3 milliseconds, or 200-250 g's peak acceleration. These estimates were made by simulating falls of children using the Motor Vehicle Manufacturers' Association (MVMA) TwoDimensional Crash Victim Simulator computer model and comparing the results with actual incidents. This study represents the only known work that specifically deals with head injury tolerance for children. 


\section{METHODOLOGY FOR TESTING SURFACES}

Test Method for Impact Attenuation

There is a history of test method development for investigating the impact attenuation capability of various products, especially protective headgear. All of the recent test methods require dropping an instrunentei headform in guided free fall and measuring some linear acceleration response of the headform during impact. Due to time and resource constraints, it was necessary, as well as desirable, for this project to take advantage of the technology already developed in this field.

Test headforms (such as the American National Standard Institute (ANSI) rigid headform, the Wayne State University resilient or hurnanoid headform, and the University of Michigan, Highway Safety Research Institute resilient head-neck system) have been and are being used for testing the adequacy of head protection provided by headgear. Of these, the ANSI rigid headform is most frequently specified in current headgear standards because it is easily reproduced and has been shown to provide reasonably repeatable results. In addition, the ANSI headform has been shown, under some conditions, to correlate with the Wayne State humanoid headform. In addition to such correlation, the acceleration responses of the two headforms was very similar. Differences in the headform response were on the order of $20 \%$, with the metal headform giving the higher accelerations $\underline{16 / .}$

In the interest of simplicity and reproducibility of test apparatus, it is proposed to test the impact attenuation capability of surfaces by utilizing the ANSI rigid headform and associated test equipment.

Furthermore, the ANSI headform gives a more conservative estimate of head response than does the resilient headform. It is further proposed to use the monorail drop apparatus, which is simplier to set up than the guidewire drop apparatus specified in the ANSI standards. Moreover, most future headgear standards are expected to specify its use.

Impact Performance Criterion

Because surfaces beneath the playground equipment are essentially flat, the likelihood of depressed skull fracture is much less than the likelihood of linear skull fracture and/or concussion. Most of the concussion data for humans (e.g., the WSU curve) were deduced from linear skull fracture data 13/. It follows, therefore, that the establishment of a performance criterion should be guided by linear skull fracture data. Also, it is advantageous to establish such a criterion in terms of peak acceleration because this greatly simplifies the testing procedure. Therefore, the most useful data for this purpose should be those where the response is measured in terms of peak acceleration when the impact load, due to head-first drop, is increased to the fracture level. Such measurements were made by Hodgson, et. al. 13/, by dropping adult cadavers 
head-first onto a flat surface. Peak accelerations in the range of 190 to $370 \mathrm{~g}$ 's were observed at the fracture level.

The impact performance criterion for surfaces should also be guided by head injury tolerance data for head-first falls of children. As indicated earlier, Mohan et. al. 15/ developed such data and estimated peak acceleration in the range of 200-250 g's as the tolerance limit. Thess: data are in good agreement with those reported by Hodgson, et. al. These data suggest that the risk of serious head injury due to head-first fal.l is minimal when the peak acceleration imparted to the head is $200 \mathrm{~g}$ 's or less. Therefore, as the impact attenuation performance criterion, it is proposed that a surface should not impart a peak acceleration in excess of $200 \mathrm{~g}$ 's to the instrumented ANSI headform. 
Materials

A survey was conducted to determine the types of surfacing materials that are, or may be, utilized as surfaces beneath public playground equipment. For this survey several playgrounds were visited, and various personnel associated with the construction and planning of playgrounds (such as school construction administrators, architects, and personnel of park commissions) were consulted. It was found that the most commonly used material is in-place soil; other materials which are often used include asphalt, concrete, crushed stone, pea gravel, rubber mats, sand, shredded tires, saw dust, tan bark, wood chips, etc.

Based on the findings of this survey and consultation with the CPSC'S technical officer, the eleven materials listed in table 1 were selected for the test program. It was decided to use two thicknesses (given in table 2) of each material to form the test surfaces. It was also decided to conduct the tests for both dry and wet surface condition for loose materials, but only for dry conditions for unitary materials (rubber mats, gym inats, and synthetic turf).

Asphalt and concrete were not included in the testing program because the data obtained by NRPA $1 /$ and by Roth and Burke 4/ indicated that, even at low velocity impacts, these materials would not meet the recommended 200 $\mathrm{g}$ criterion. Soil was not included because it was felt that the test results would not be meaningful due to the wide variations in composition and conditions that may occur from one geographic location to another.

Specimen Size

Since the cross-sectional area of the test surface may affect the test results, particularly for surfaces composed of loose material, a series of. preliminary tests were conducted to determine the appropriate specimen size. These tests were conducted with sand in square containers having sides of $8,12,18$ and 24 inches* in length. The results are presented in figure 2 for four different drop heights. These tests indicate that the change in headform response is negligible for containers with sides exceeding 18 inches. Based on these results, an $18 \times 18$ inch container was selected for testing loose materials. For unitary materials, such as mats and synthetic turf, it was subjectively judged that the specimen should be at least 6 by 9 inches.

Headforin and Drop Apparatus

The monorail drop apparatus (figure 3) and the size "C" ANSI headform equipped with accelerometer were used for testing the impact attenuatior performance of the test surfaces. The headform was attached to its support assembly, which guides the headform on the monorail during free $f a l$. The base of the monorail was surrounded by a 26 by 24 by 12 inch container,

*Quantitative data contained in this report are presented in the U.S. Customary Inits of measure. The following equivalents can be used to derive the metric units: inches X $2.54=$ centimeters; feet $\times 0.3048$ meters. 
which housed the surfacing material under test. The surface beneath the test material consisted of a solid steel block, which was 14 inches in diameter and 6 inches thick.

The height of the drop apparatus used in the test program limited the maximum distance through which the test headform could be dropped to 10 feet or less. It is recognized that some playground equipment extends to greater heights, hence consideration was given to investigating a procedur that would permit testing at greater drop heights. A suggested procedure is to spring load the headform guidance assembly at the top of the apparatus prior to release. This provides a greater velocity than that acquired in free fall, thereby increasing the effective drop height. Results of testing indicate that this procedure is feasible. However, time and resource limitations precluded the testing of surfacing materials at extended drop heights.

\section{Instrumentation}

A velocity meter was used to measure the velocity immediately before impact.

A piezoelectric linear accelerometer, placed at the center of mass of the headform, was used to measure the acceleration imparted to the headform. The output of the accelerometer was channeled through a signal conditioner and charge amplifier and then into a storage oscilloscope ant also into a Severity Index (SI) analyzer. The instrumentation, with the exception of the SI analyzer, was selected and operated in accordance with SAE Practice J211b requirements for channel class 1000.

\section{Test Procedures}

Loose Materials. Loose materials to be tested were placed in the 18 by 18 inch frame containing the steel block base (i.e., the base surface) to form as even a surface as possible. The depth of the material directly above the steel block was maintained at either 4 or 6 inches.

The instrumented headform was dropped (first drop) on this surface from various heights and data (impact velocity, peak acceleration imparted to the headform, SI, velocity change experienced by the headform, and pulse duration) were recorded. The headform was dropped a second time (second drop) into the depression left by the first drop from the same height, and data were recorded. After the second drop, the surface was leveled and brought back to the initial thickness; the above procedure (the first and second drop) was repeated at least twice without changing the drop height. The tests were repeated at increased drop heights until the headform response exceeded either an SI value of 1000 or a peak acceleration value of $250 \mathrm{~g}$ 's.

This procedure was followed for all of the loose materials tested. Tests were conducted with 4 and 6 inch material thicknesses and with both dry and wet surface conditions. For wet conditions, the surfacing material 
was soaked for at least 15 hours in a separate container and transferred to the test container for the wet test; before testing, the excess water was drained from the material by means of a sump pump. After the tests were completed at one drop height, the test surface was resaturated by sprinkling one gallon of water on the surface and draining off the excess.

Unitary Materials. A specimen of the test material, as provided by the manufacturer, was placed on the steel block base (base surface). The headform was dropped on the test surface from various heights and data recorded. The test was repeated at least twice at each drop height. In some cases, double thicknesses of the material were tested. As with the loose materials, the procedure was repeated at increased drop heights until the headform response exceeded either an SI value of 1000 or a peak acceleration value of $250 \mathrm{~g}$ 's. 


\section{TEST RESULTS AND DISCUSSION}

Presentation of Test Results

Impact attenuation performance data were obtained in terms of peak acceleration response of the headform as a function of impact velocity. Because friction in the guidance system of the headform drop apparatus can vary from one apparatus to another, as well as from test to test, impact velocity is a more significant measurement parameter than drop height. The equivalent free fall height, $H$, may be calculated from impact velocity, $\nabla$, as

$$
\mathrm{H}=\mathrm{V}^{2} / 2 \mathrm{~g}
$$

where $\mathrm{g}$ is the acceleration due to gravity.

Other variables were monitored during the tests (SI, velocity change, and pulse duration) but are not necessary for evaluating the impact attenuation performances of surfaces; they are not presented here.

Figures 4 through 25 show peak acceleration as a function of impact velocity for different materials. The result of each drop and a least squares fit of each series (except those in figures 13 and 21) are provided on each plot. The nature of the materials yielding the data in figures 13 and 21 required alternative methods for summarizing the data. Figure 13 depicts a curve obtained from an exact fit (a quadratic over a linear expression) of four $\left(x_{i}, y_{i}\right)$ pairs where the $y_{i}$ are the average peak accelerations for each of the four clusters of ${ }^{i} x_{i}$ (velocity). The trace of figure 21 through the points obtained from tests ${ }^{1}$ using wet material (0- on this plot) comprises two line segments. The relatively horizontal segment resulted from a least squares fit of the data. The near-vertical segment was formed by passing a line through the end point of the least squares trace and the average velocity and peak acceleration of the three outlying observations.

The curves of figures 4 through 25 are presented to summarize the observed dependence of peak acceleration on velocity (or, equivalently, free fall distance). One of two regression models

$$
y=a+b x+e
$$

or

$$
y=a+b x+c x^{2}+e
$$

was used for analysis.

Intuitively, a first or second degree (i.e., linear or quadratic) model probably best illustrates the underlying relationship between stimulus and the observed physical response. Higher order models will 
always provide a better fit to observational data, but this contradicts the premise of simple monotonic relationships. In consequence, if a poor fit is indicated between model and data, this may be attributed either to instrumentation error or to the test material itself. In these experiments, the accuracy of the equipment was repeatedly checked by means of an established calibration procedure, hence any systematic error is probably due to the lack of homogeneity in the composition of the material.

Information to determine the adequacy of fit of a model to the data is contained in the residuals, that is, the deviations of the actual observed values about the values predicted by the model. (A thorough discussion on testing the adequacy of fitted models can be found in Draper and Smith, 1966 17/). In brief, the sum of squared residuals can be decomposed into two parts: a component due to "pure error" and the other due to "lack of fit." Dividing each component by its associated degrees of freedom results in the mean sums of squares for "pure error" $\left(S^{2}\right)$ and "lack of fit" (MS ), respectively. The usual procedure to test the adequacy of the model is to form the ratio,

$$
\text { F-ratio }=\frac{M S_{L}}{S_{e}^{2}}
$$

and obtain the corresponding percent point of the F-distribution having the appropriate degrees of freedom. If this percent point is less than some specified rejection criterion, say the 95th percent point (corresponding to a level of significance, $\alpha=0.05$ ) there is no reason to reject the model. Table 3 provides the necessary information to determine how well each model fits the data; namely, the F-ratio and its corresponding percent point.

Discussion

It can be observed from figures 4 through 25 that, in general, wet surfaces performed better than dry surfaces. One exception was material G (cocoa shell mulch, see figure 21). When wet, this material bottomed out abruptly, resulting in peak accelerations which exceeded the proposed criterion.

The data of figure 21 are of particular interest. They show that the performance of material $G$ (wet) changed abruptly from a set pattern at a certain impact velocity, suggesting that other materials (both wet and dry) might also exhibit similar behavior at impact velocities beyond the range of the test impact velocities. It is recommended that the test data presented for a given material should not be used to predict performance at higher impact velocities than shown.

As might be expected, these data also indicate that, in general, the thicker surfaces (thickness b) performed better than thinner surfaces (thickness a). One exception was material C (pea gravel). For this material performance was not noticeably affected by a change in the surface 
thickness. Material $\mathrm{C}$ also provided poor impact attenuation (see figures 5 and 17), so would not meet the proposed criterion.

For purposes of comparison, the performance of surfaces with thicknesses "a" and "b" of all materials tested are reproduced in figures 26 and 27 respectively. An examination of these figures reveals that most loose materials performed better than the unitary materials, and $F$ (pine bark nugget), performed the best of all the materials tested.

Figure 28 shows the data for the first and the second drops (see test procedure) for both thicknesses of material A, while figure 29 shows the second drop data for thickness "a" of all materials. These data indicate that, for loose materials, the peak acceleration response of the test headform is considerably higher for the second drop than for the first drop. This phenomenon apparently occurs because the loose material is pushed away and somewhat packed by the first drop, so that the second drop is essentially on a surface of lesser thickness. In actual use, this phenomenon may also occur as a result of routine activities such as jumping or running on the surface material. Consequently, a surface consisting of loose material would require regular maintenance to insure constant effectiveness. One alternative might be to install the material in sufficient thickness to reduce the effects of casual jumping and running; this may reduce the frequency of maintenance. 


\section{CONCLUSIONS}

The impact attenuation performance of surfaces, in relation to head injury due to falls from playground equipment, can be tested by dropping the instrumented ANSI headform on the surface and measuring the acceleration response of the headform. As the impact attenuation performance criterion, it is proposed that a surface should not impart a peak acceleration in excess of $200 \mathrm{~g}$ 's to the instrumented ANSI headform. Surfaces composed of six inches of loose materials such as pine bark, sand, shredded tires and shredded wood bark imparted peak accelerations which were below this limit for drop heights up to 10 feet. Surfaces composed of one layer of unitary material exceeded the criterion at drop heights of 5 feet or less.

The scope of this project did not permit an in-depth examination of the performance of surfaces at higher impact velocities or of the effects that a range of material thicknesses, compaction, and moisture content would have on impact attenuation performance. Further testing would be required to fully evaluate these factors. 

TABLE 1. Surfacing Materials Tested

Designation
All purpose sand
Whole tire crumb, $1 / 2$ inch shreds
Pea gravel, 3/8 inch mesh
Pine bark, mini-nuggets
Shredded hardwood bark
Pine bark nuggets
Cocoa shell mulch
Crushed stone (blue stone dust)
Outdoor rubber mat, 1 1/2 inches thick
Indoor gym mat, $11 / 2$ inches thick
Synthetic turf on 3 inches thick asphalt base
(turf was bonded to resilient pad)

Material Description 
TABLE 2. Surmary of Tests Performed

\begin{tabular}{|c|c|c|c|c|}
\hline Surfacing & \multicolumn{2}{|c|}{$\begin{array}{l}\text { Surface Thickness } \\
\text { (inches) }\end{array}$} & Surface & nditions \\
\hline Material & (a) & (b) & Wet & Dry \\
\hline A & 4 & 6 & $\mathrm{X}$ & $x$ \\
\hline B & 4 & 6 & $\mathrm{X}$ & $x$ \\
\hline C & 4 & 6 & $X$ & $x$ \\
\hline D & 4 & 6 & $x$ & $x$ \\
\hline E & 4 & 6 & $x$ & $x$ \\
\hline F & 4 & 6 & $x$ & $x$ \\
\hline G & 4 & 6 & $x$ & $x$ \\
\hline $\mathrm{H}$ & 4 & 6 & $x$ & $x$ \\
\hline I & Single & Double ${ }^{1}$ & & $\mathrm{X}$ \\
\hline $\mathrm{J}$ & Single & Double ${ }^{1}$ & & $\mathrm{X}$ \\
\hline $\mathrm{K}^{2}$ & $3 / 8$ & $5 / 8$ & $x^{3}$ & $X$ \\
\hline
\end{tabular}

${ }^{1}$ One pad on top of the other formed the test surface.

${ }^{2} 3 / 8$ and 5/8 inch thickness indicates the thickness of the resilient pad between the turf and the asphalt base.

${ }^{3}$ Only the surface with thickness "b" was tested wet. 

造

N CC

i

$\stackrel{2}{\mathrm{C}} \underset{0}{\mathrm{~L}}$

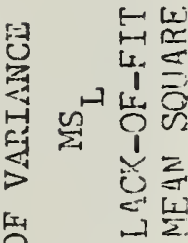

乐焉

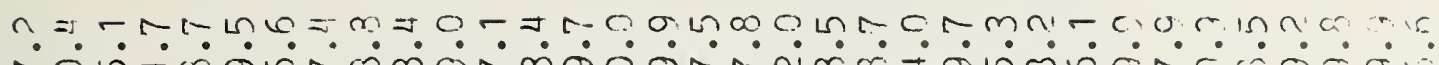

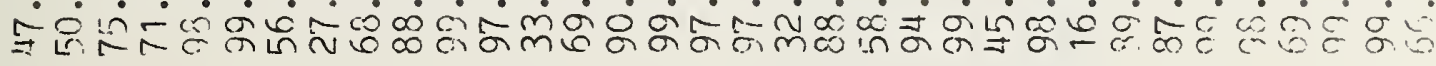

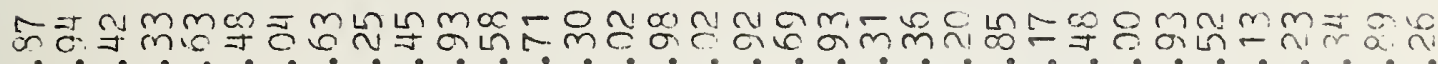

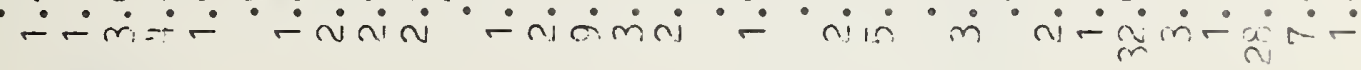

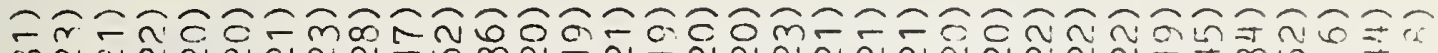

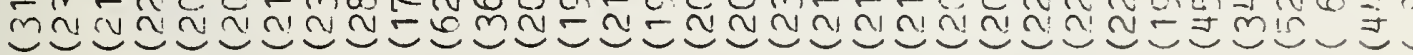

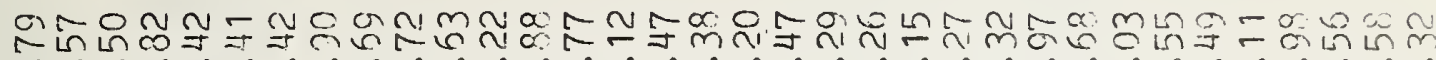

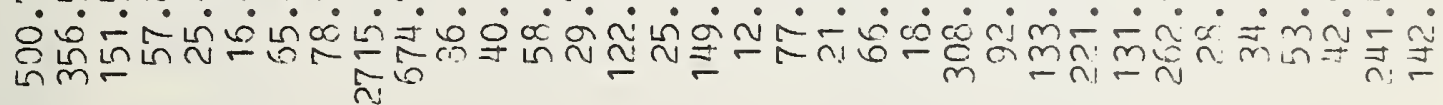

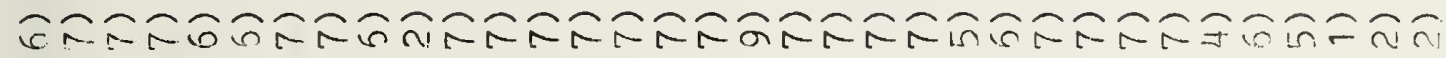
$\smile \smile \smile \smile \smile \smile \smile \smile \smile \smile \smile \smile \smile \smile \smile \smile \smile \smile \smile \smile \smile \smile \smile \smile \smile \smile \smile \smile \smile \smile \smile \smile \cdot \smile$

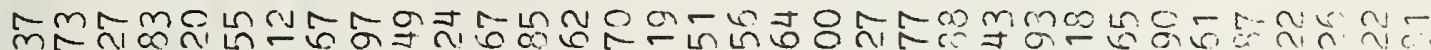

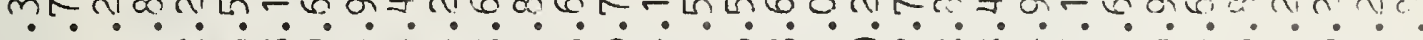

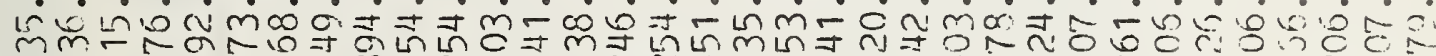
桨西

$\widetilde{L}$

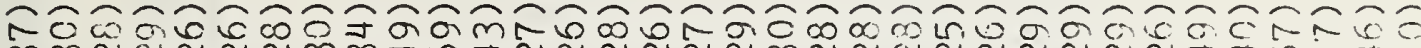

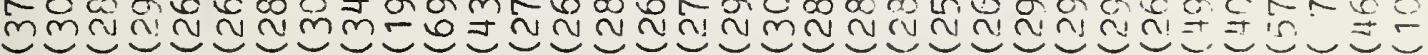

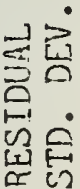

N

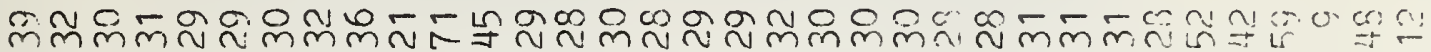

Jน

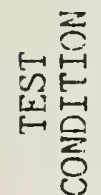

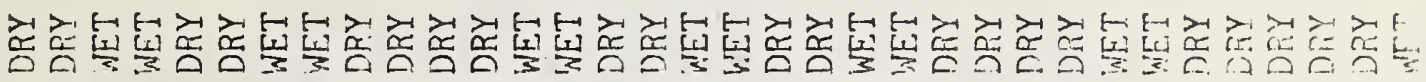

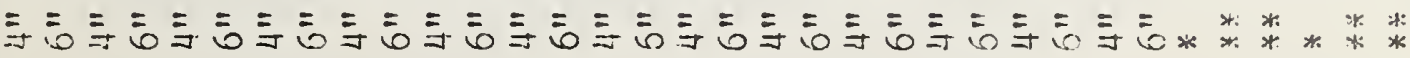

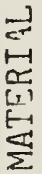

๔ 



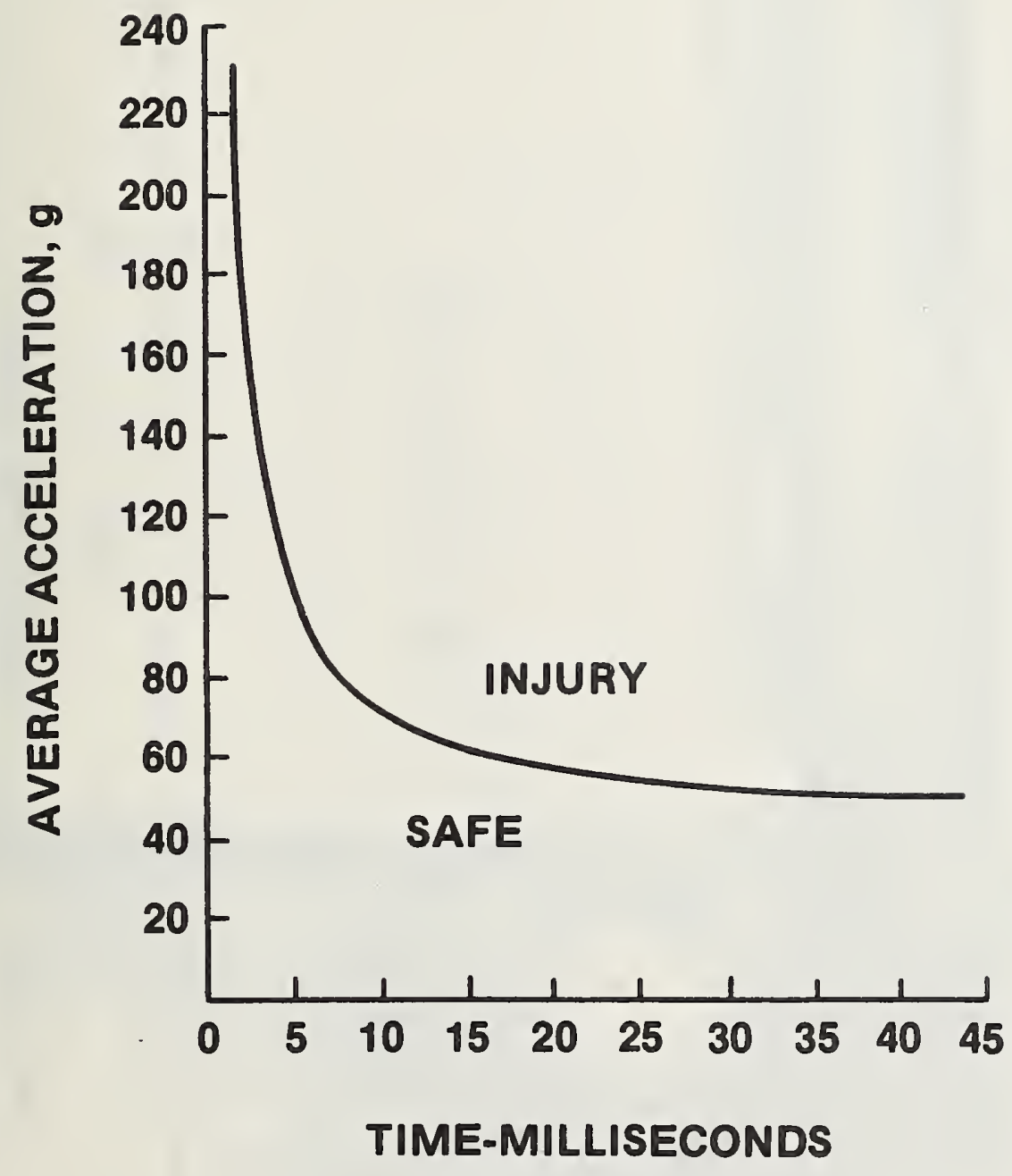

Figure 1. Wayne State Concussion Tolerance Curve. 


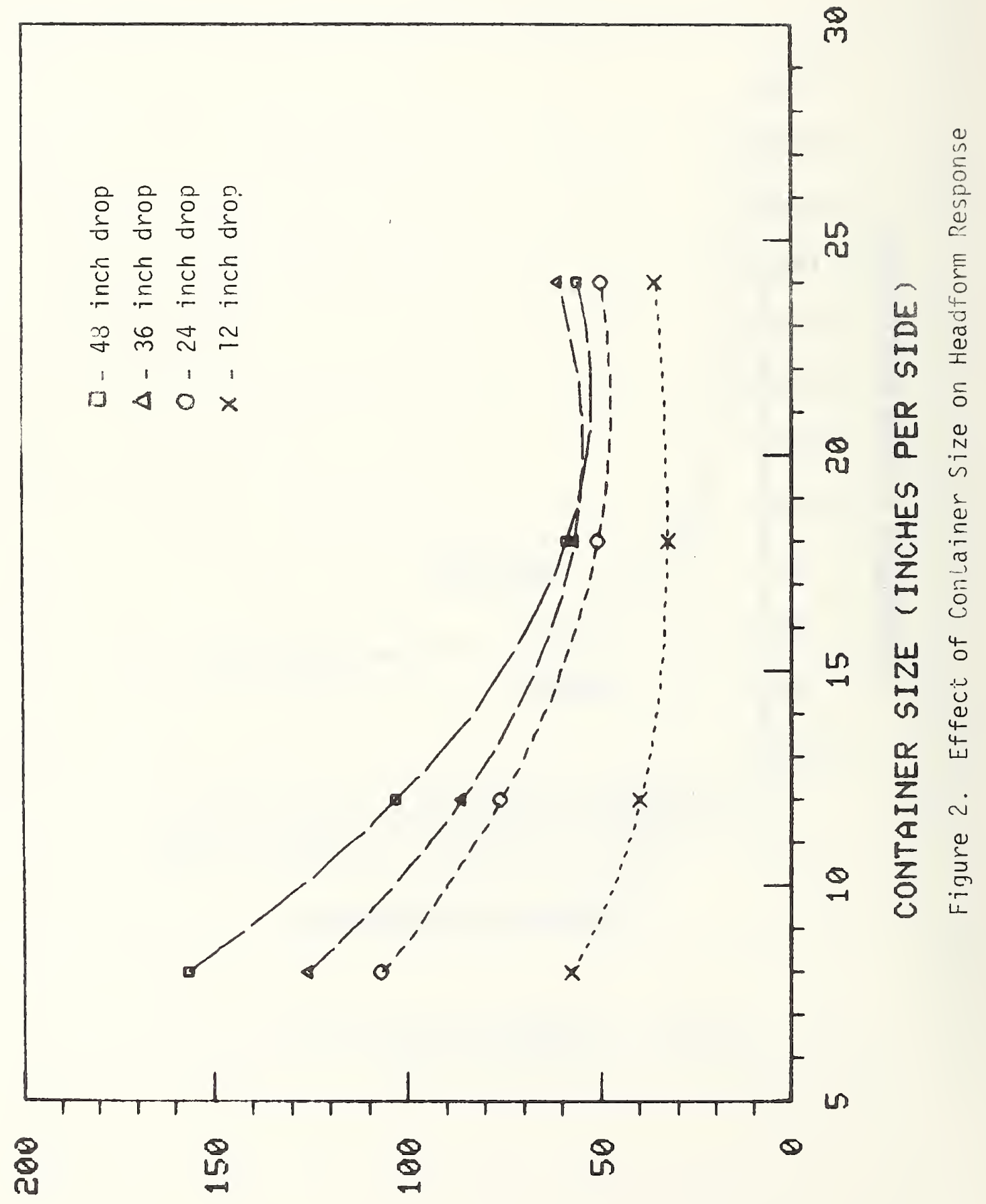

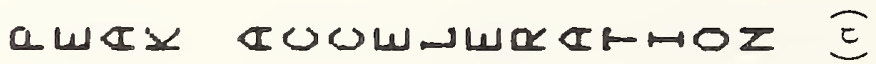




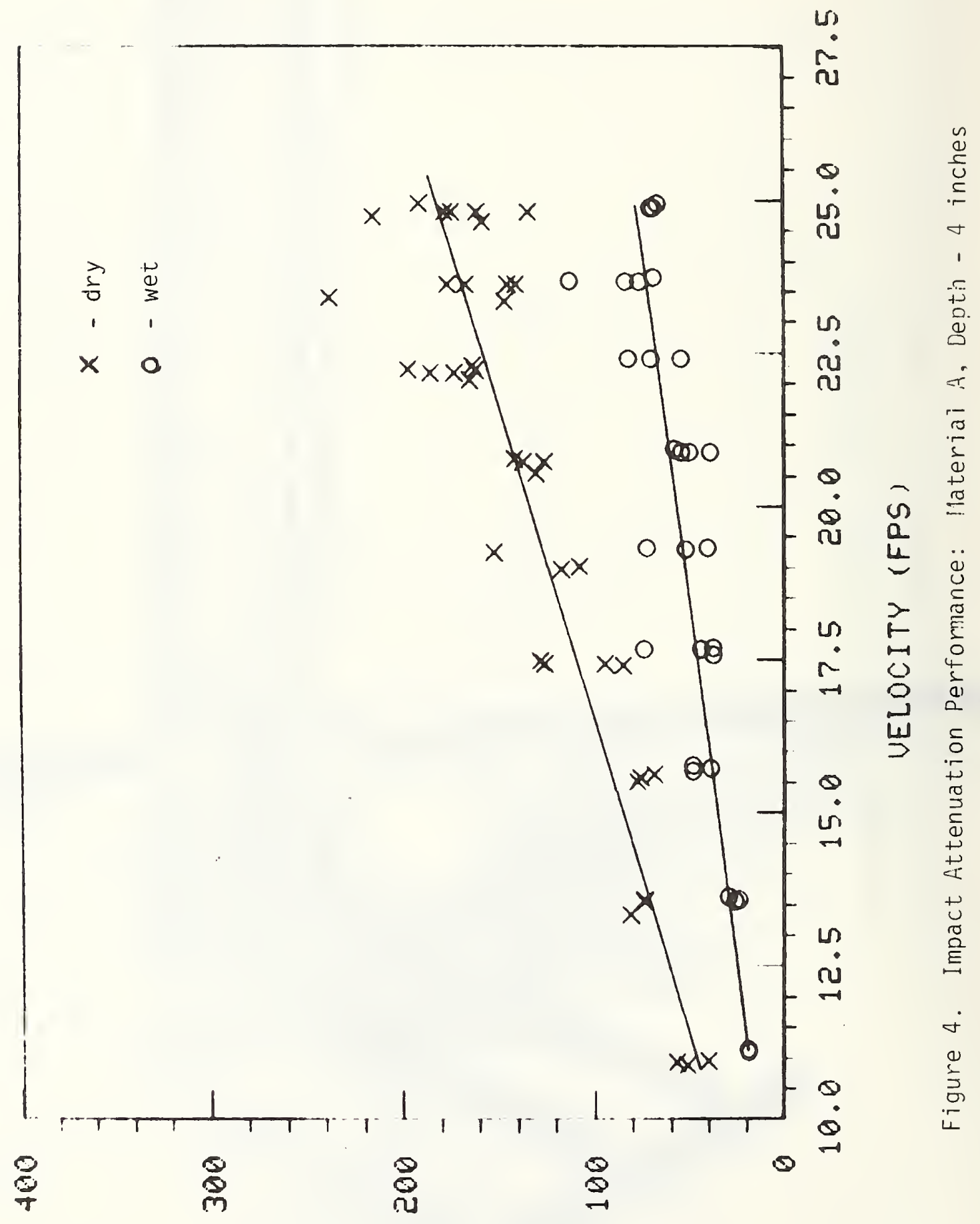

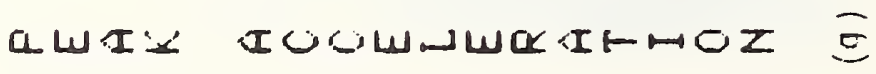




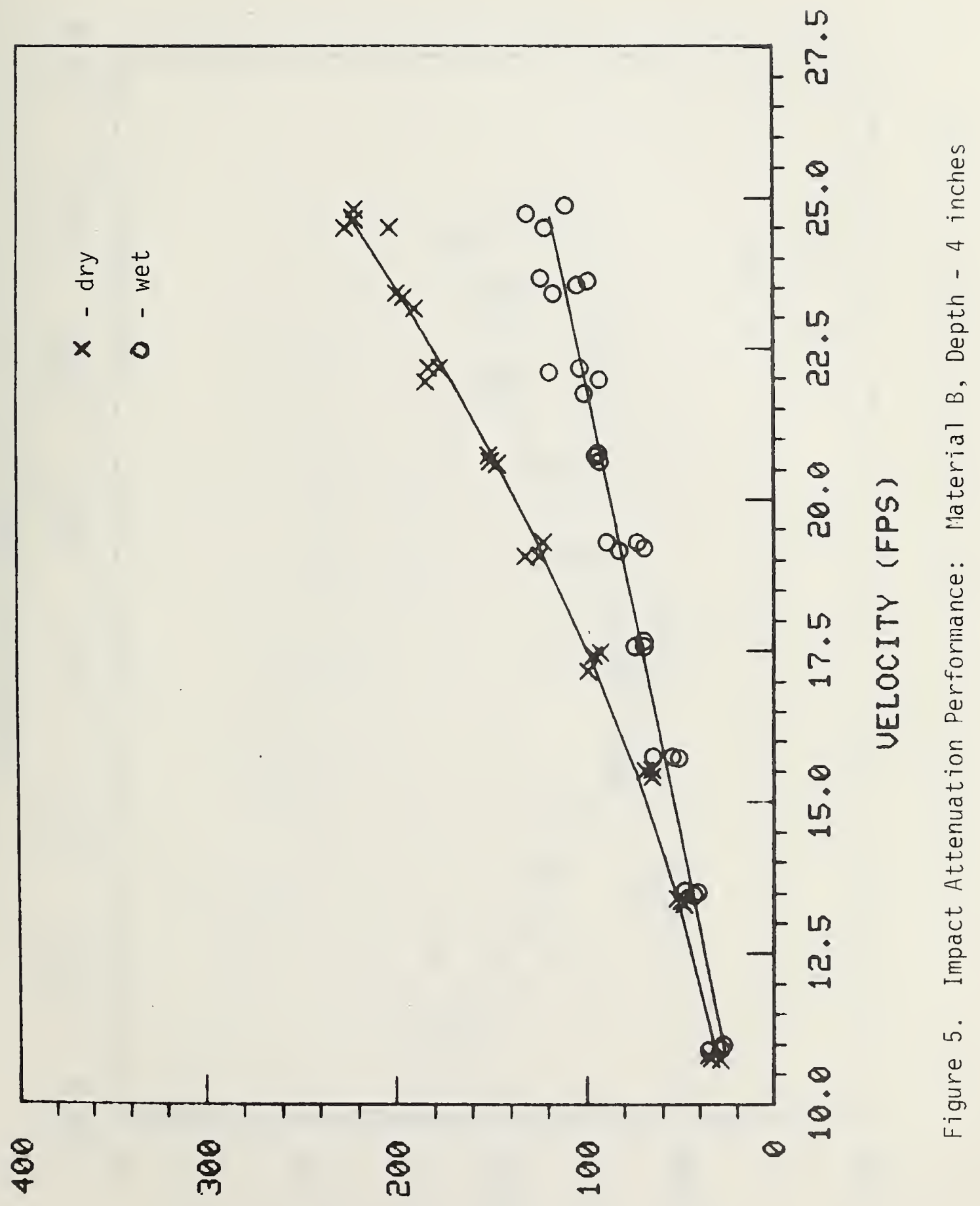

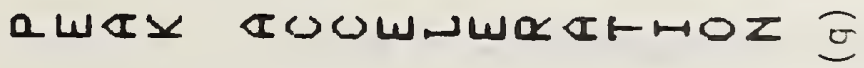




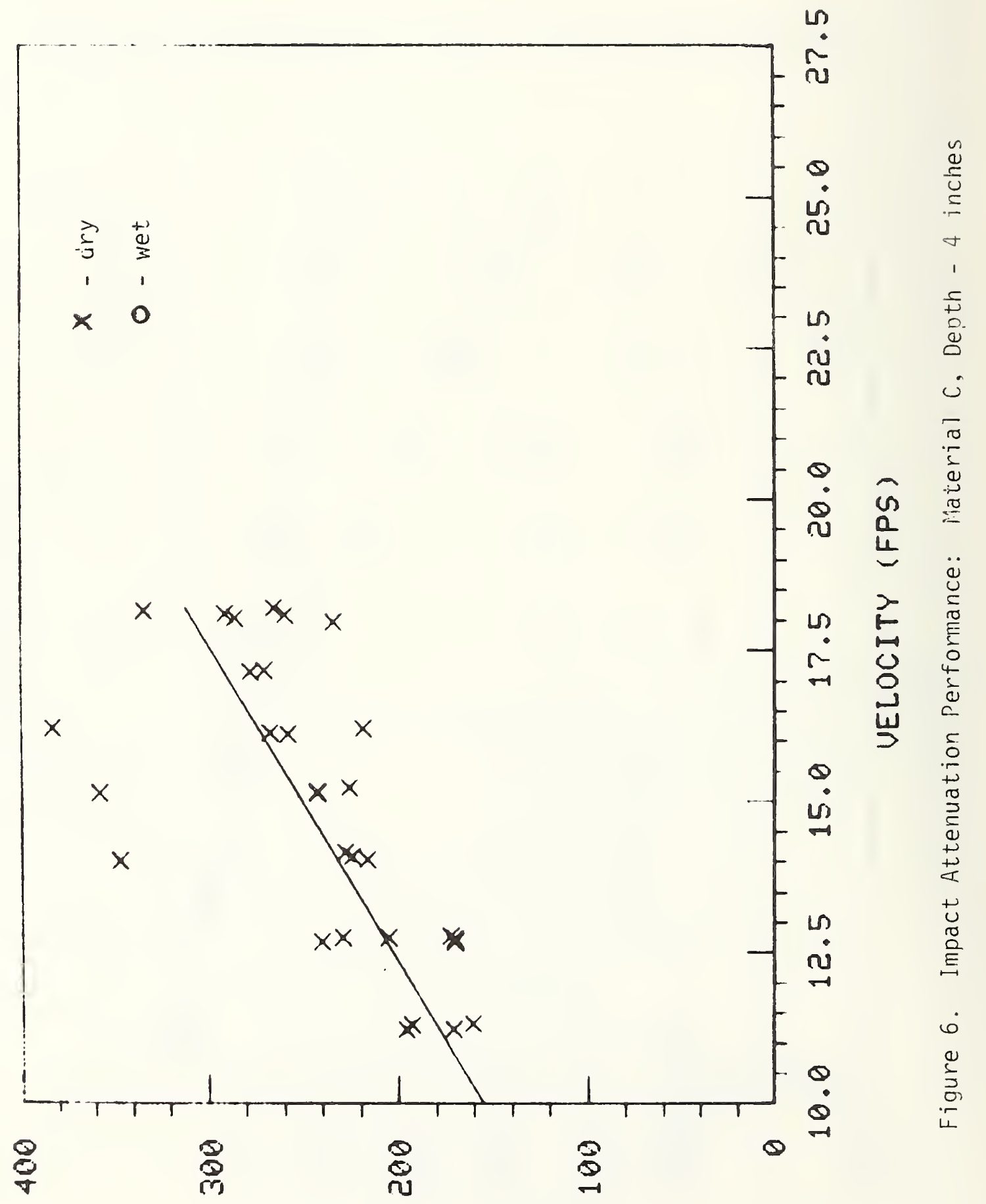

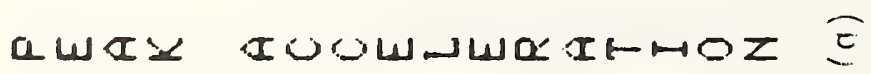




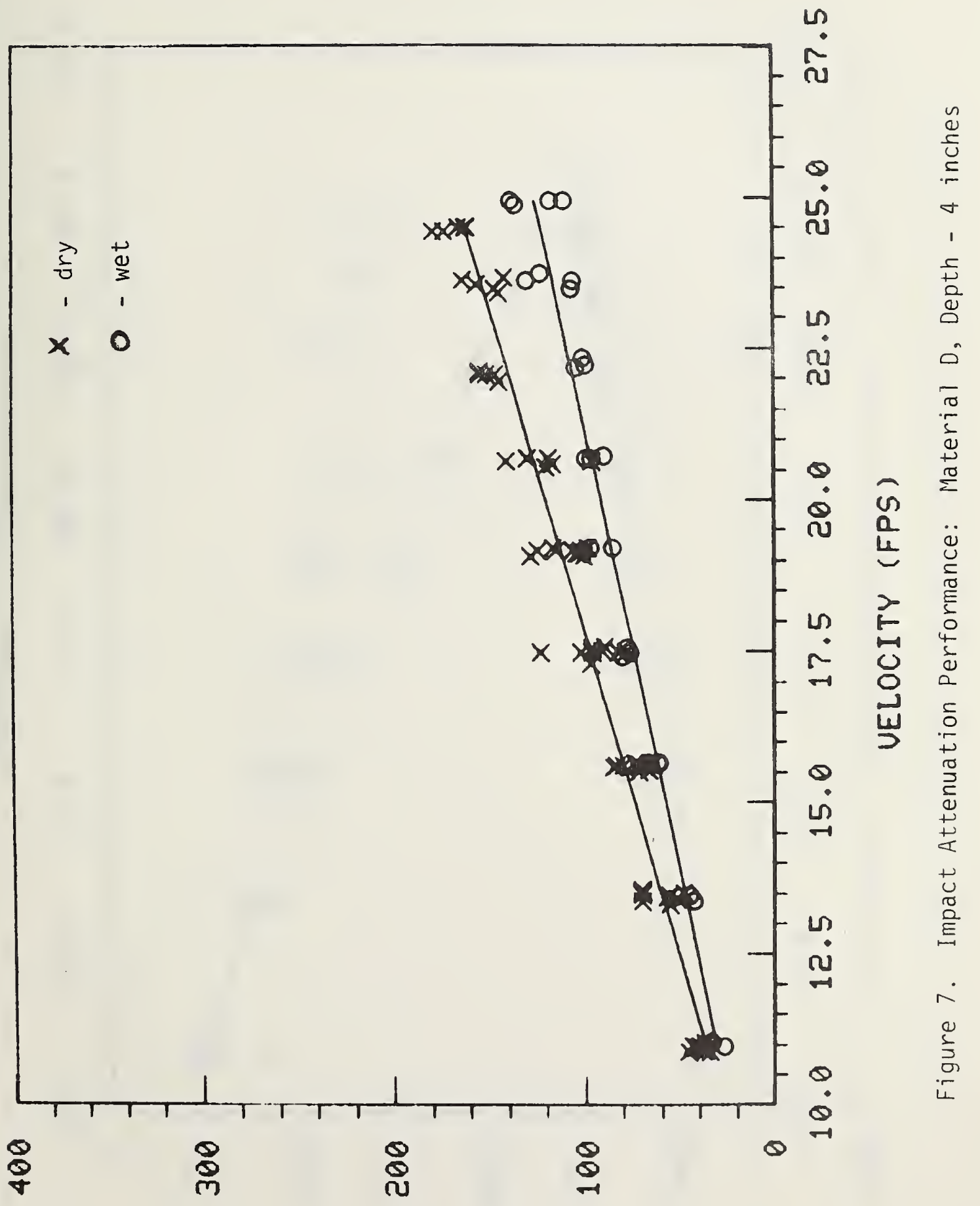

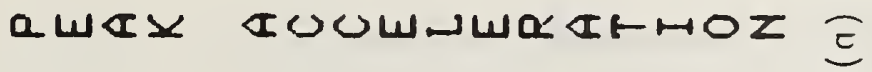




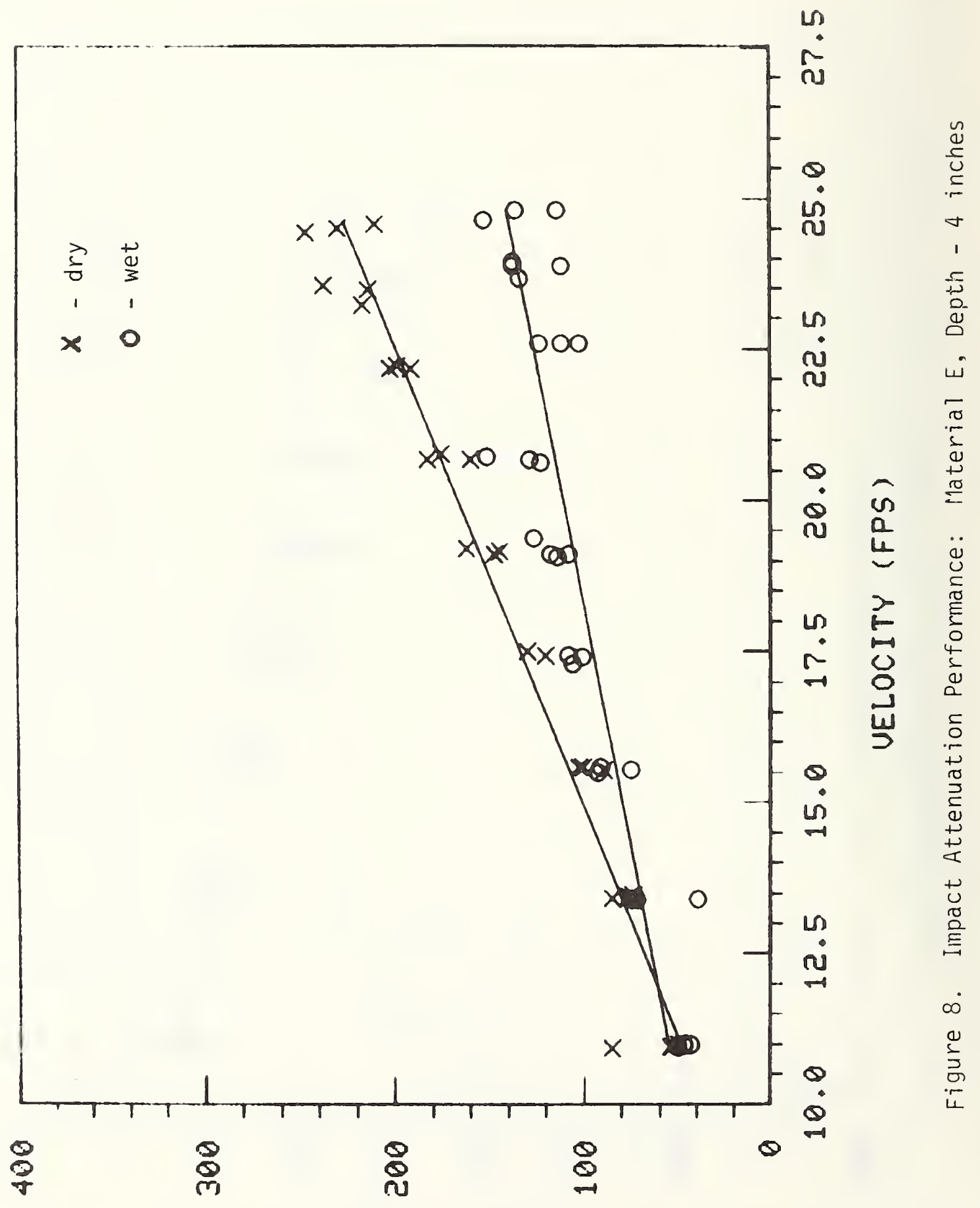

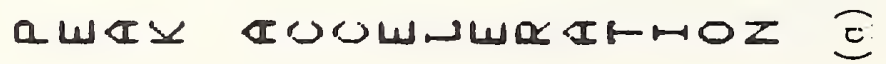




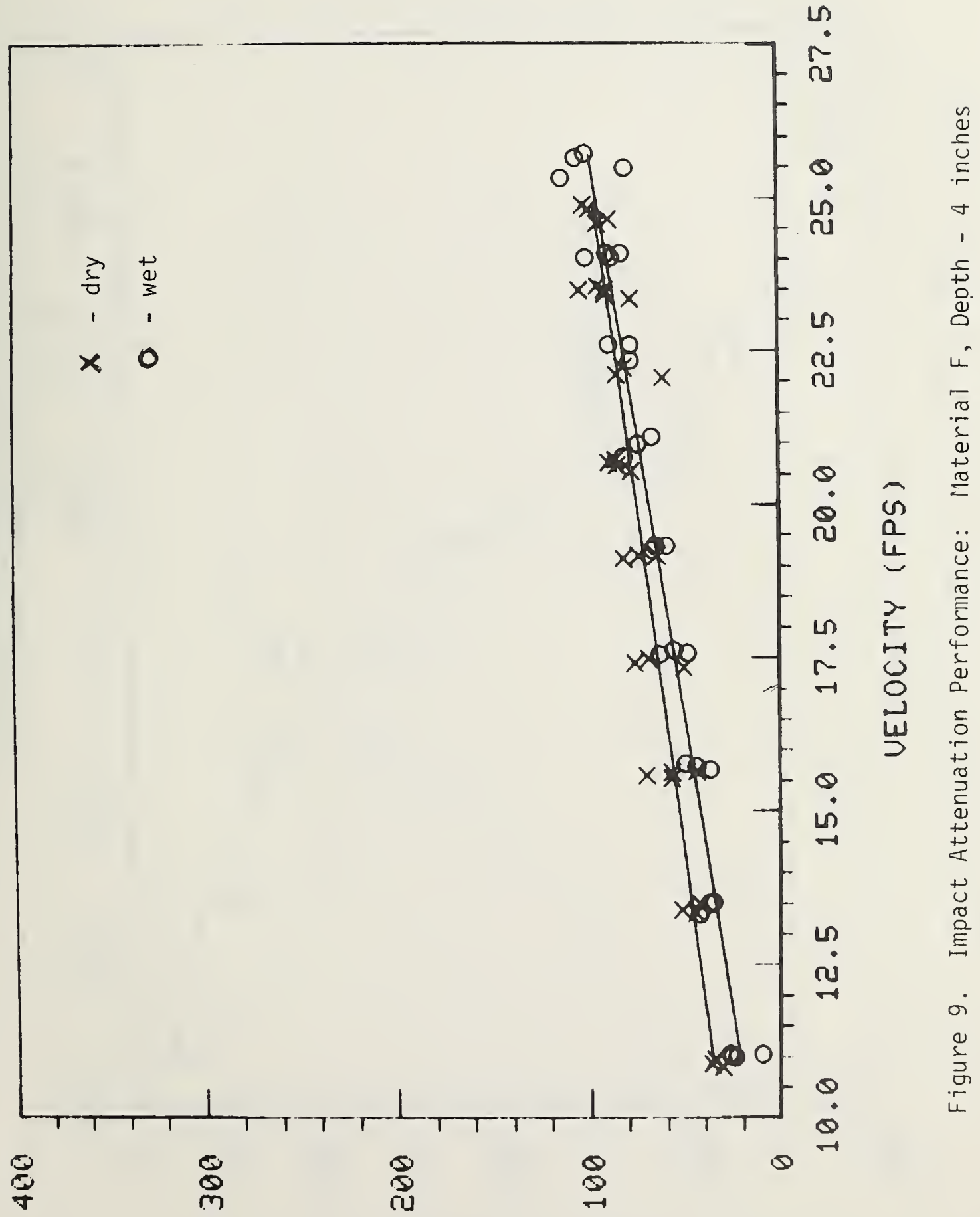

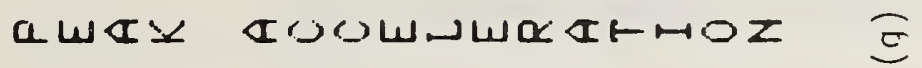




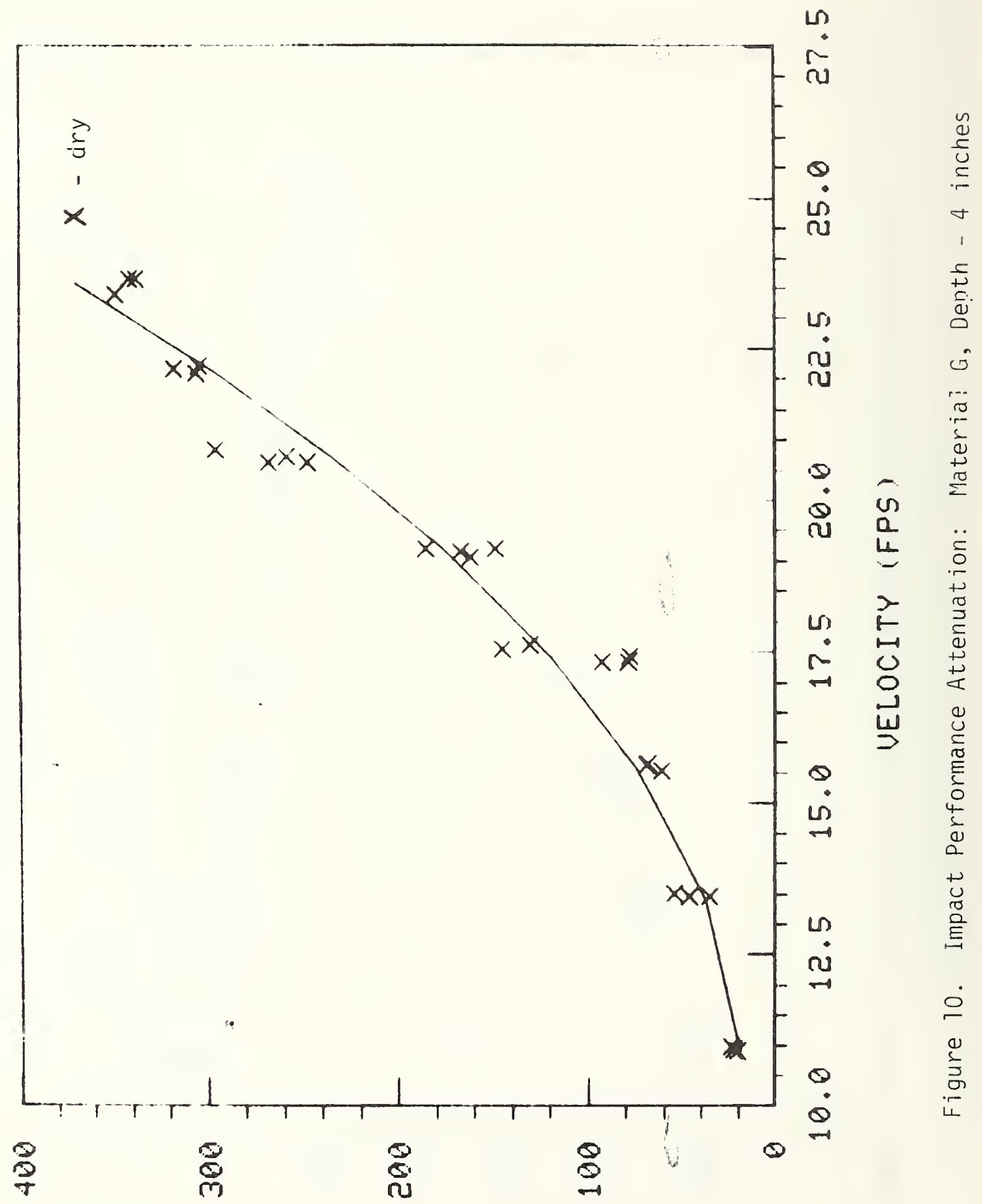

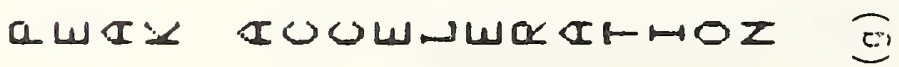




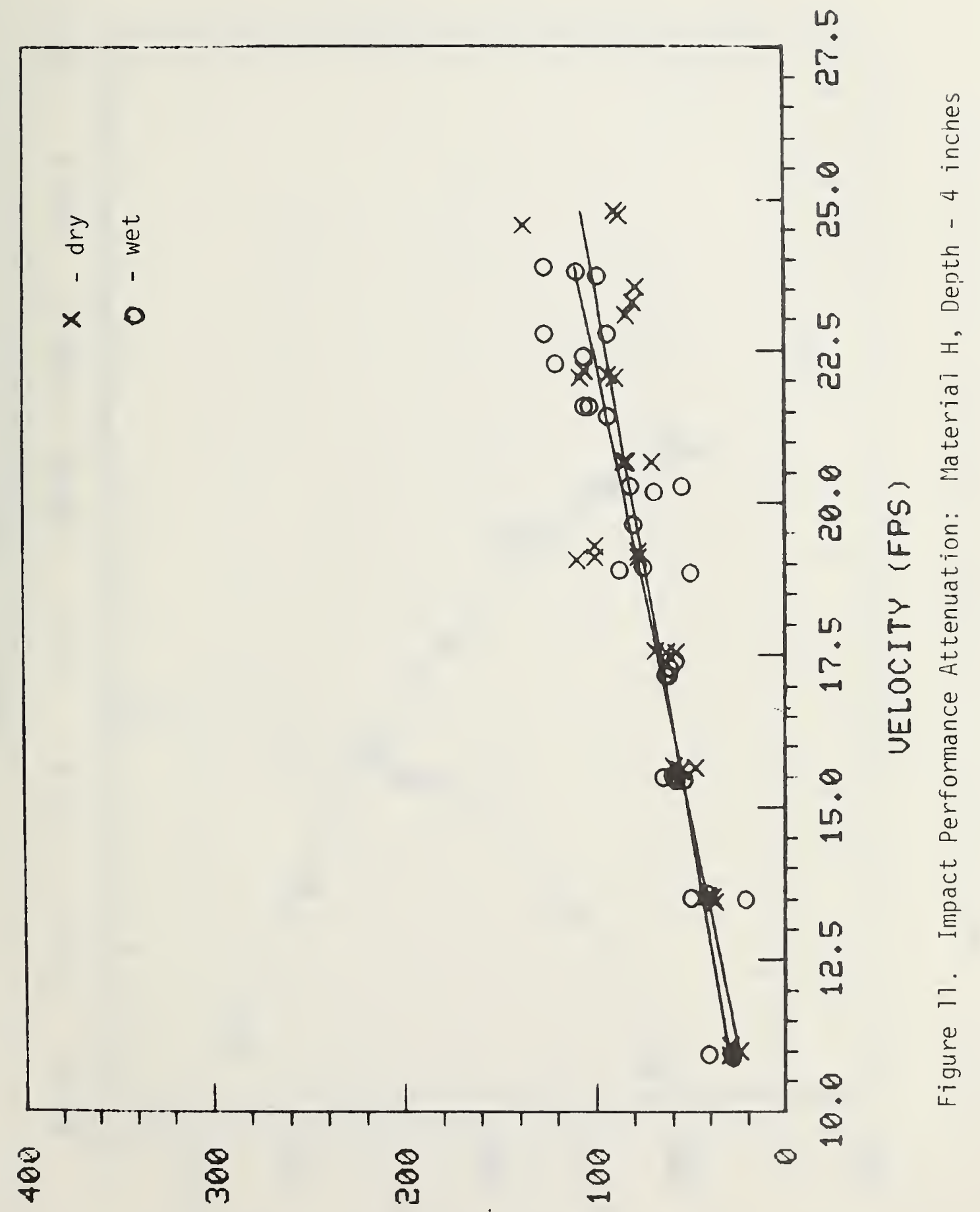

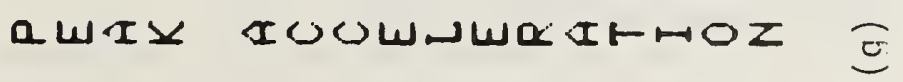




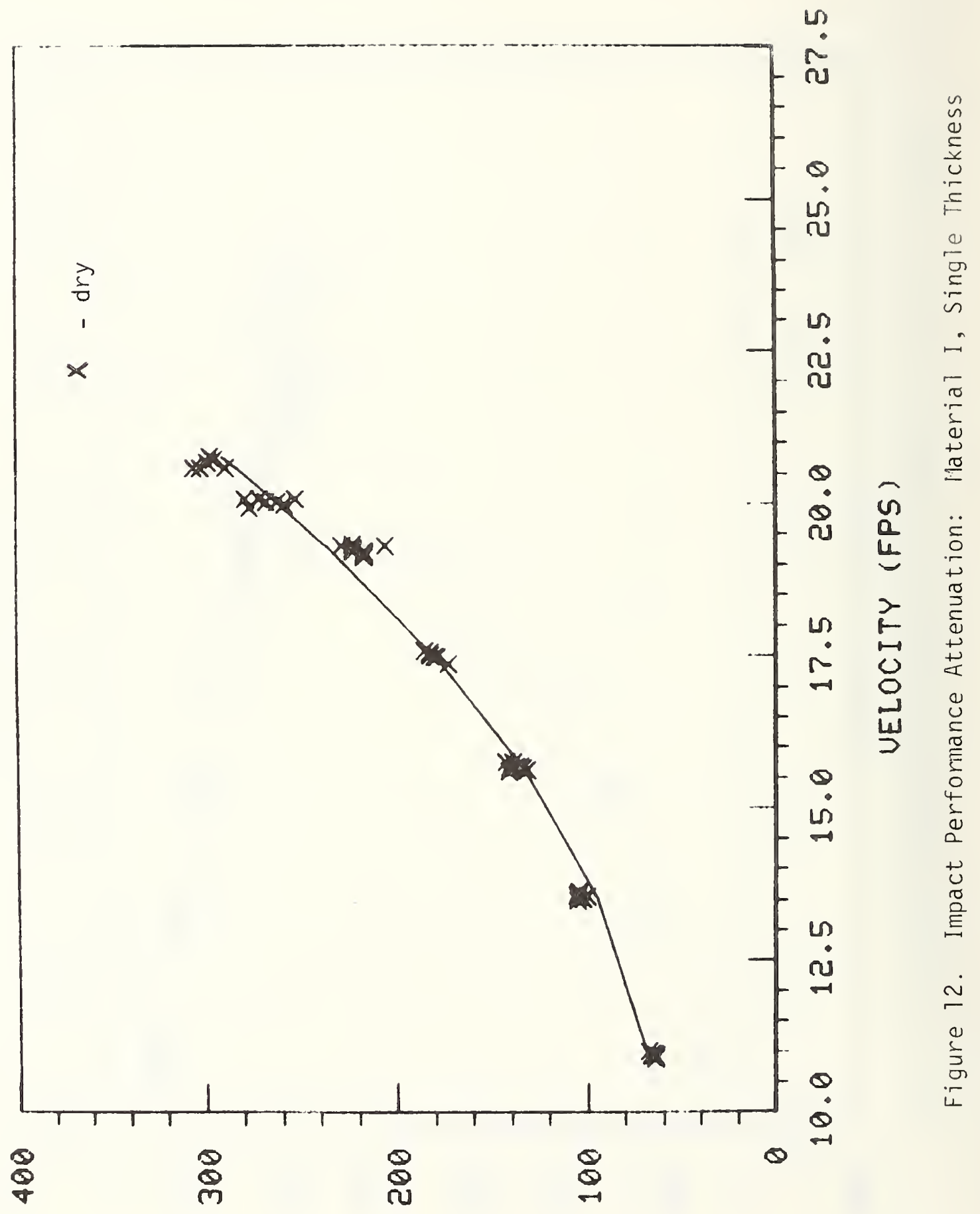

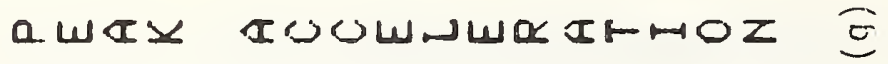




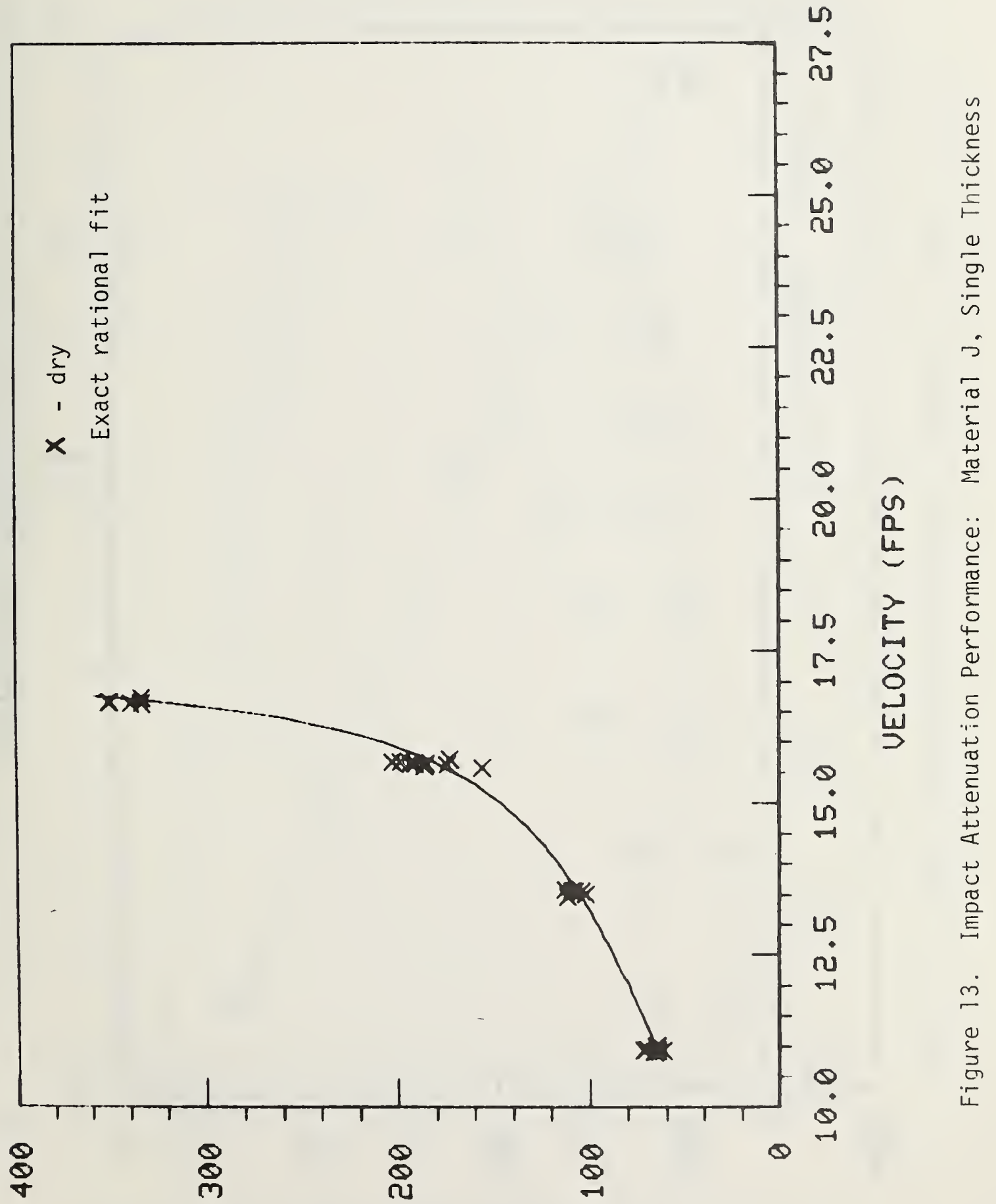

aw 


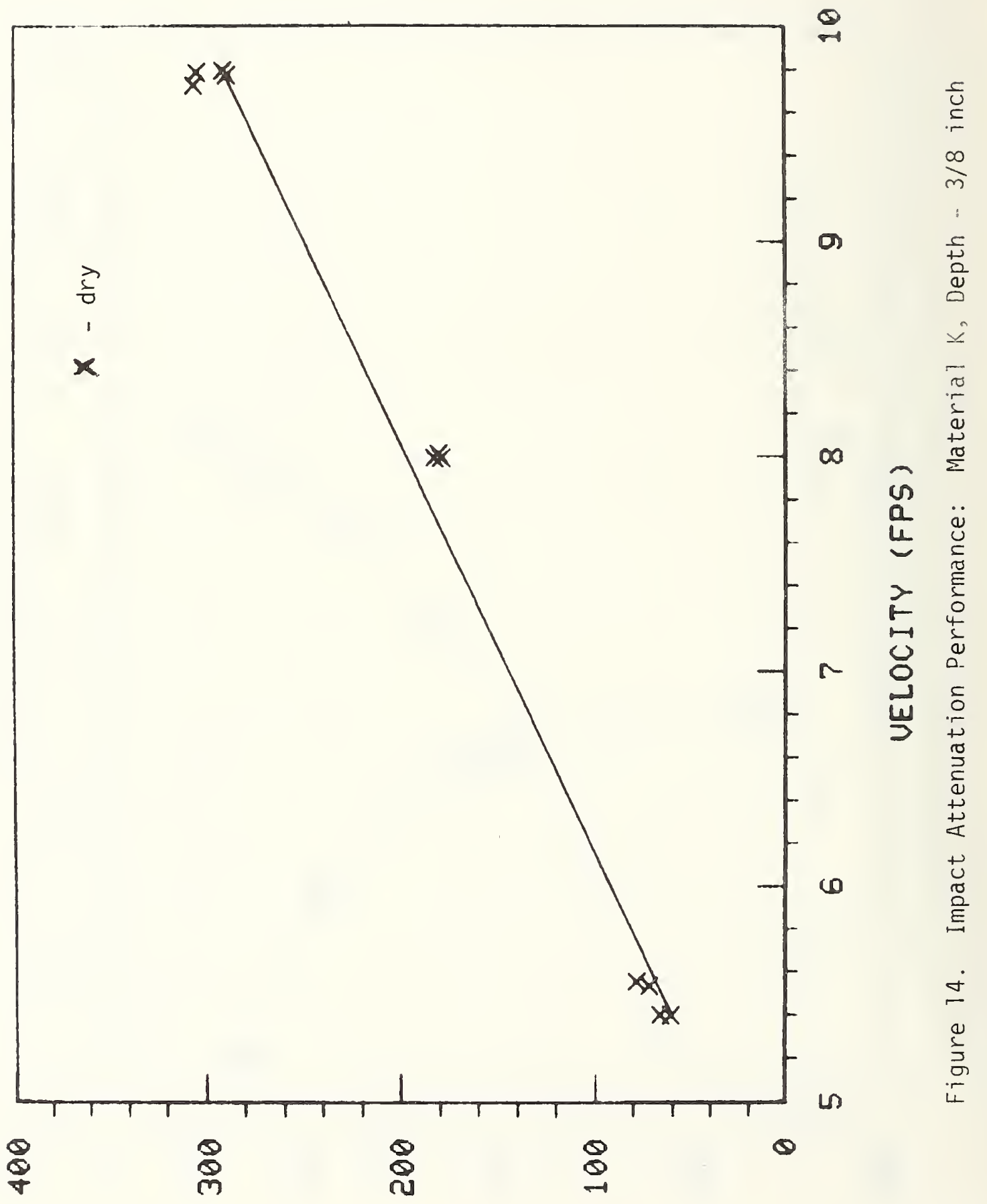

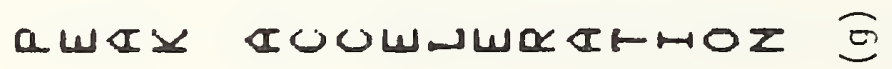




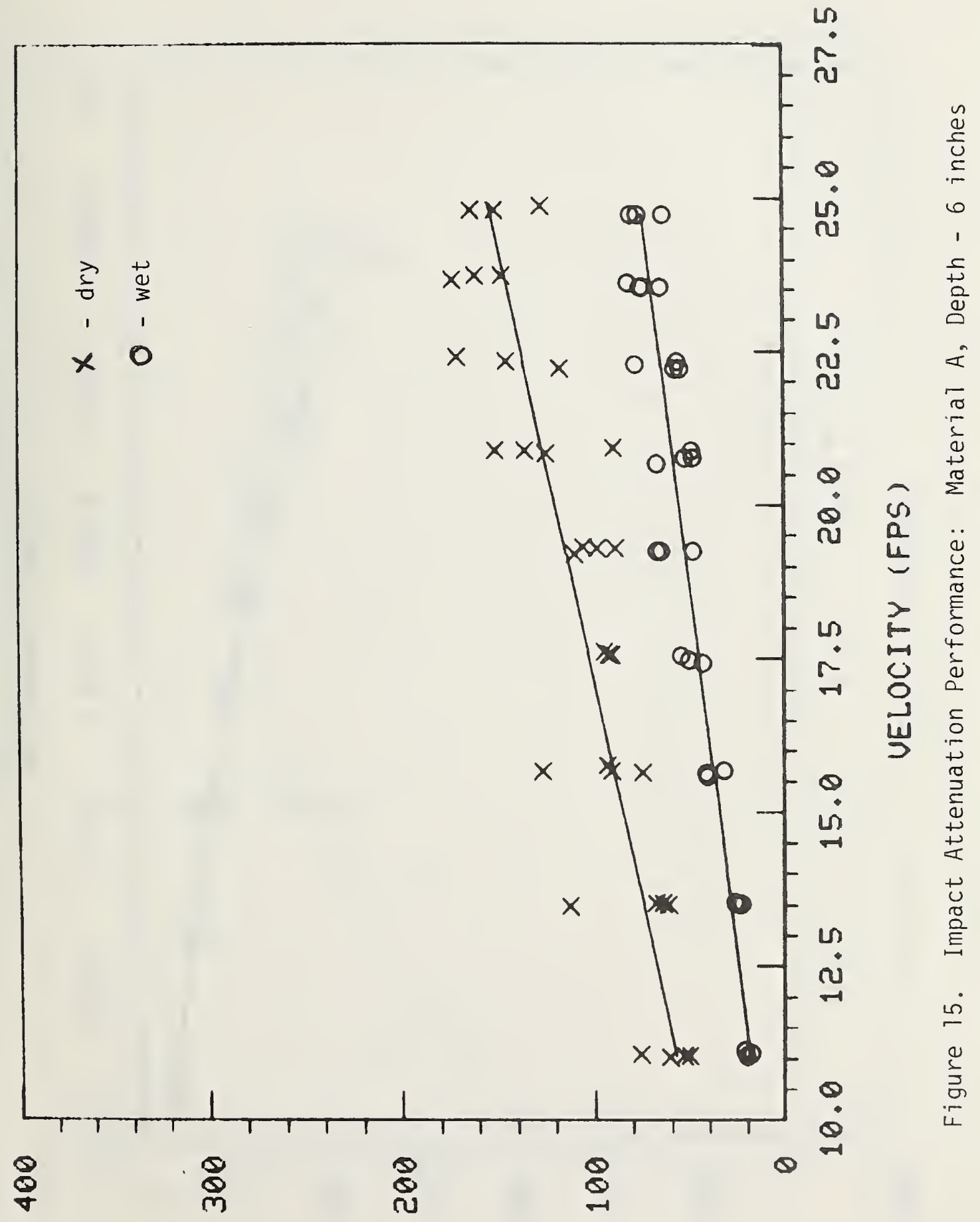

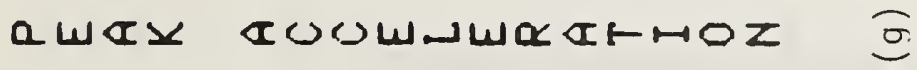




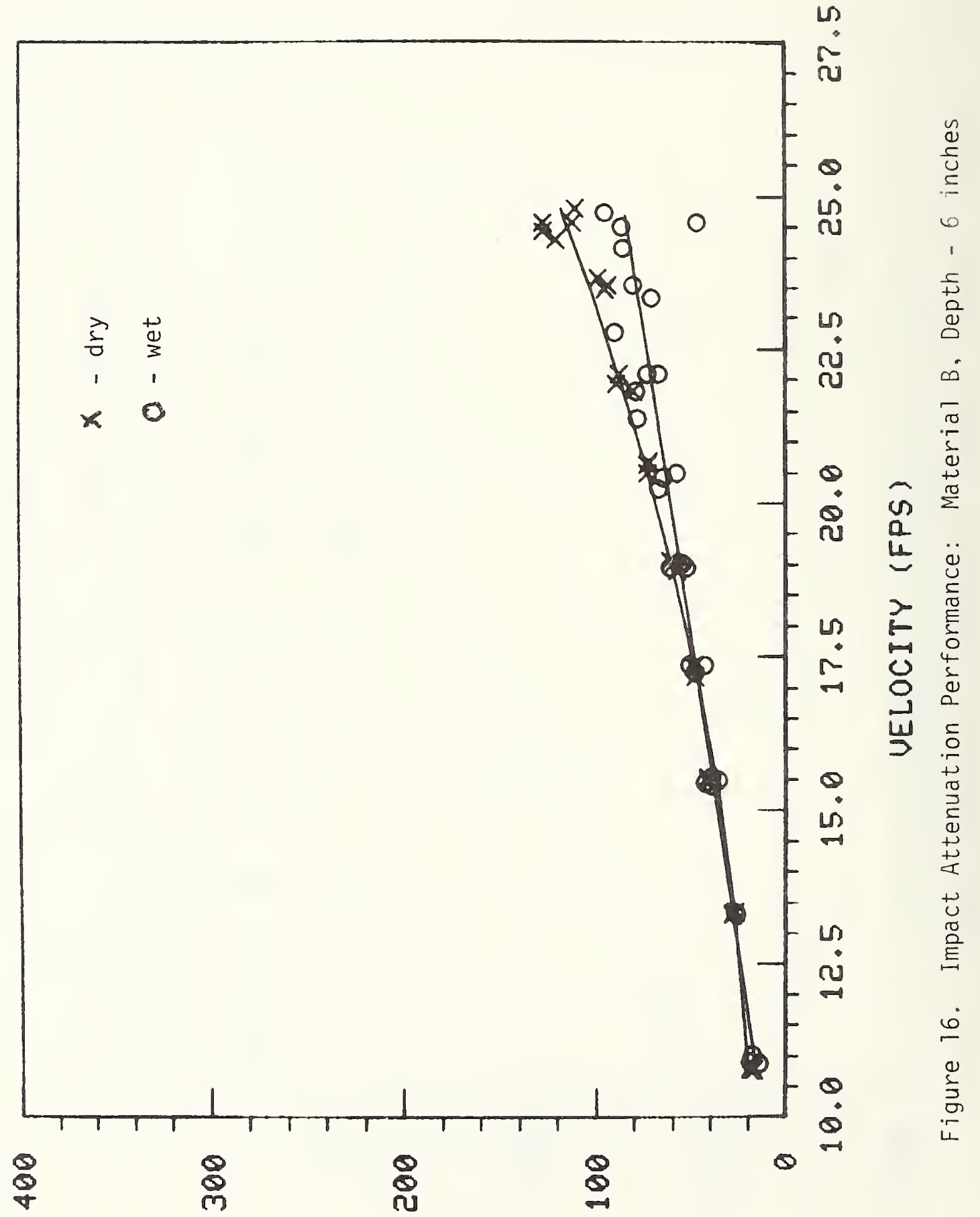

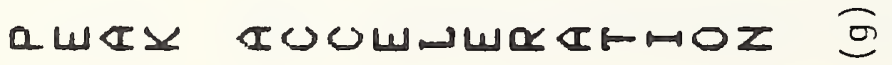




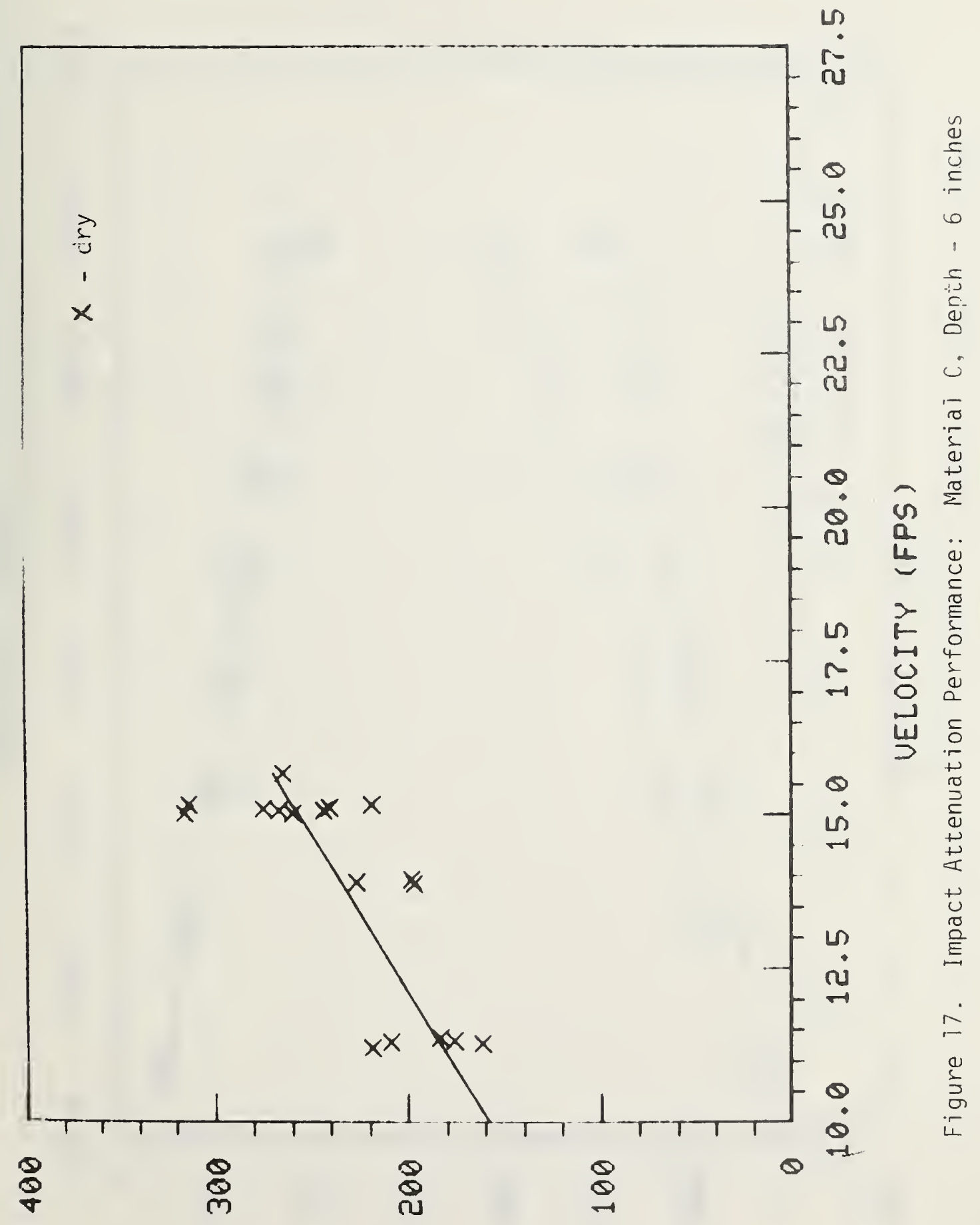

ロ 


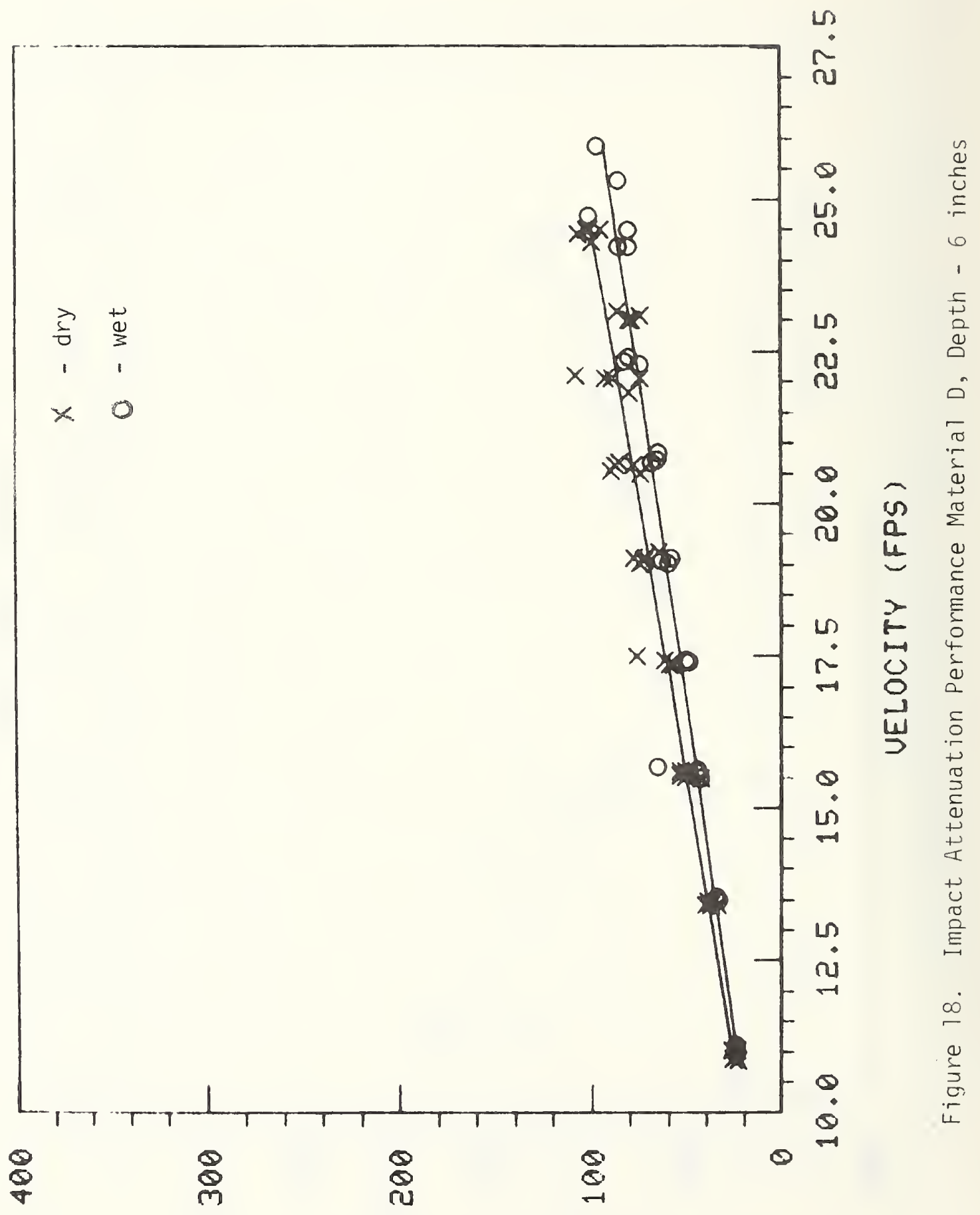

aWIX IPSWmWRIFमOZ E़ 


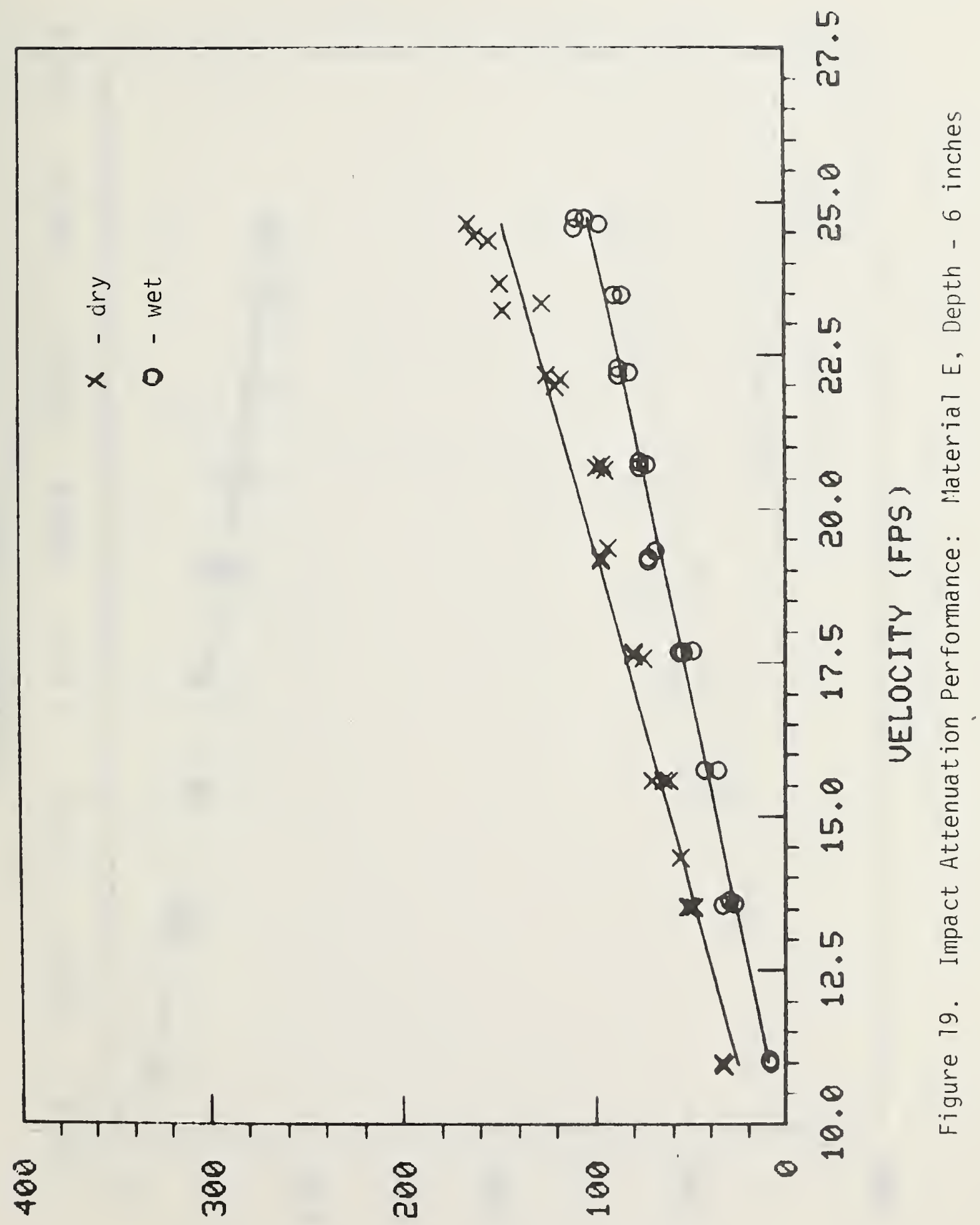

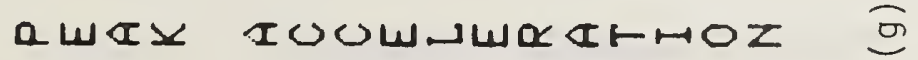




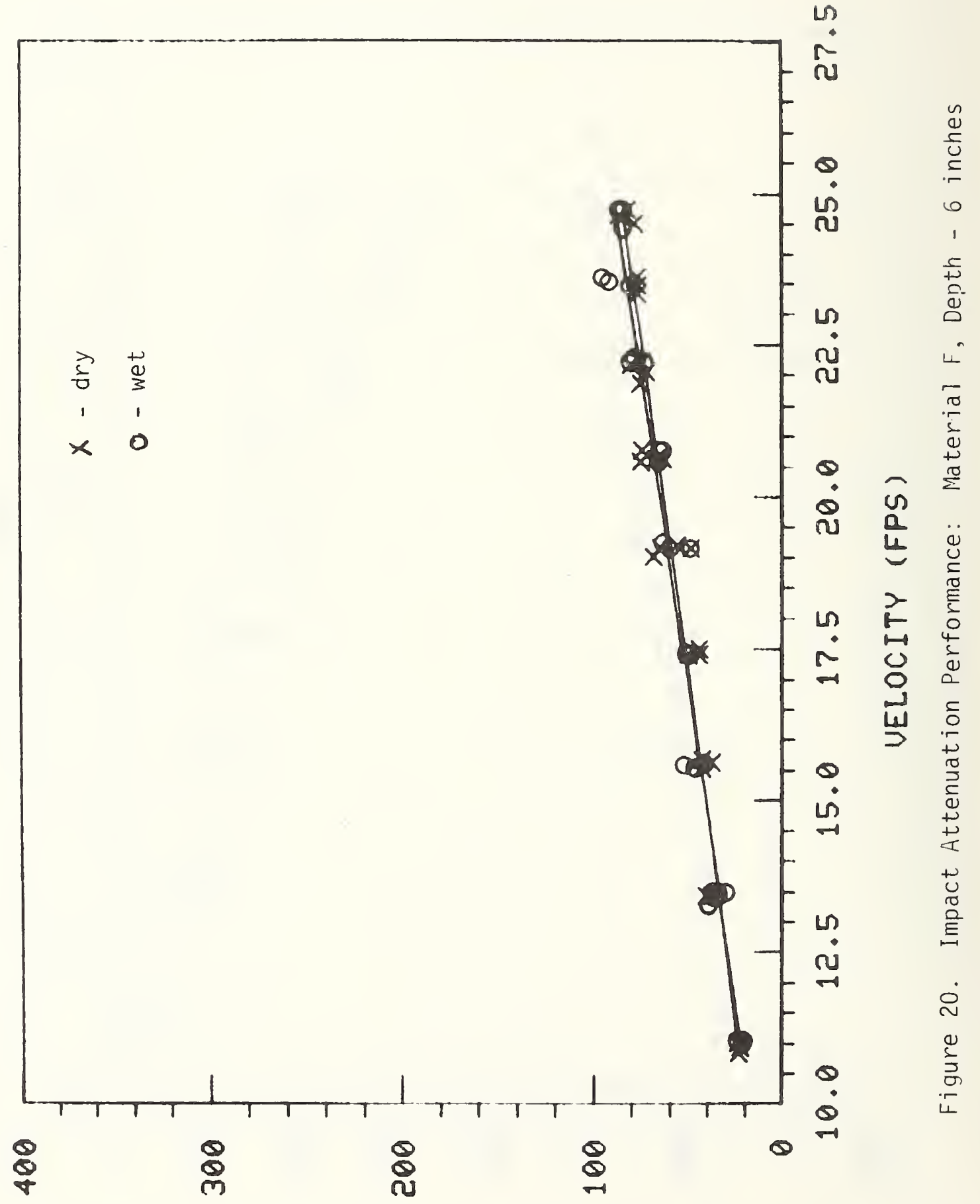

away IUOWDWoarmoz Ẽ 


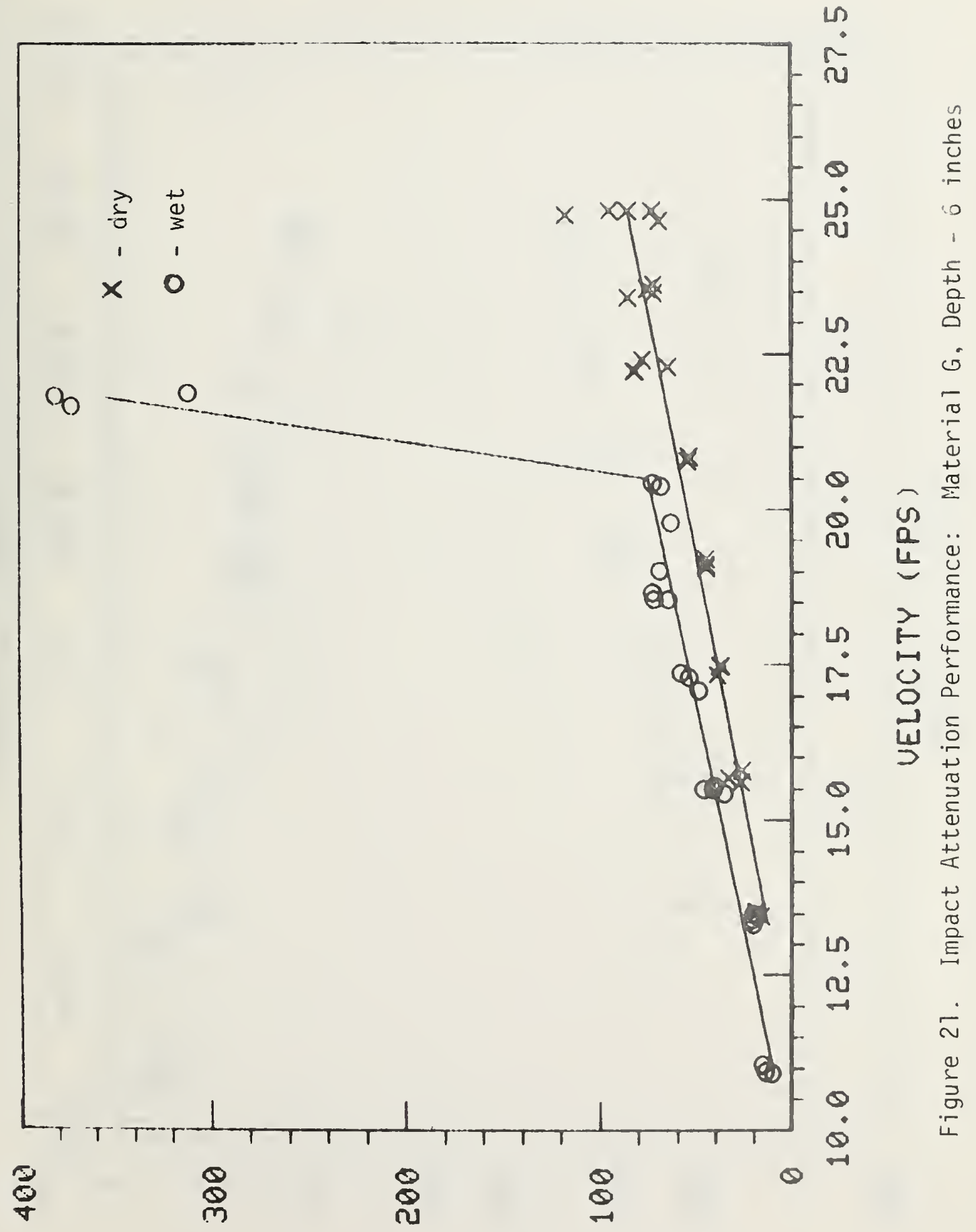

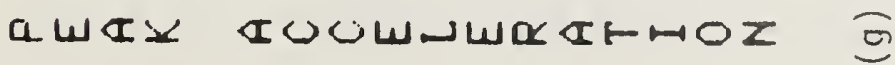




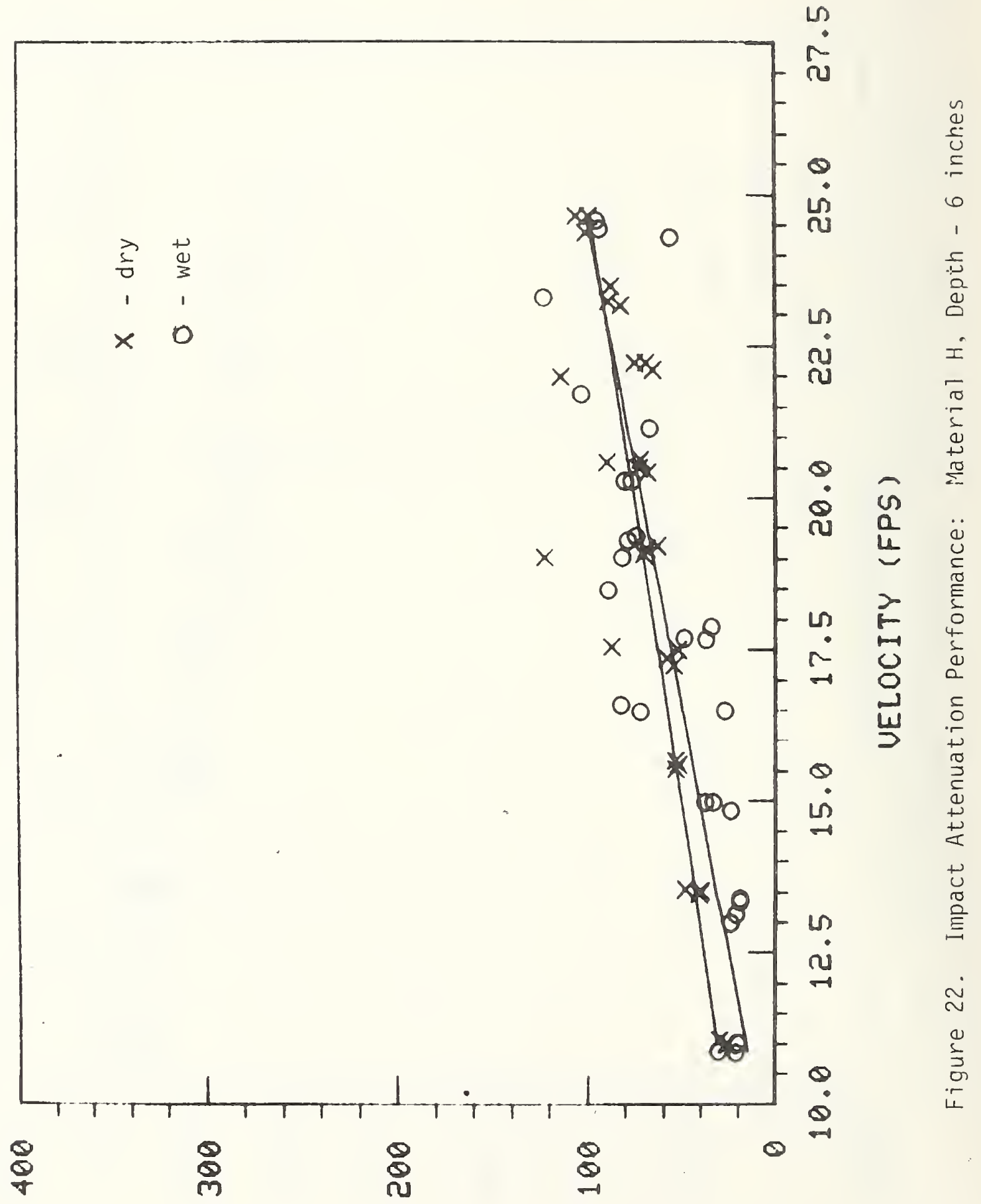

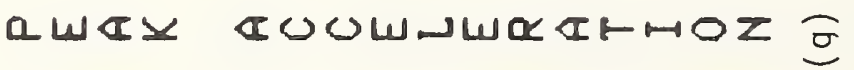




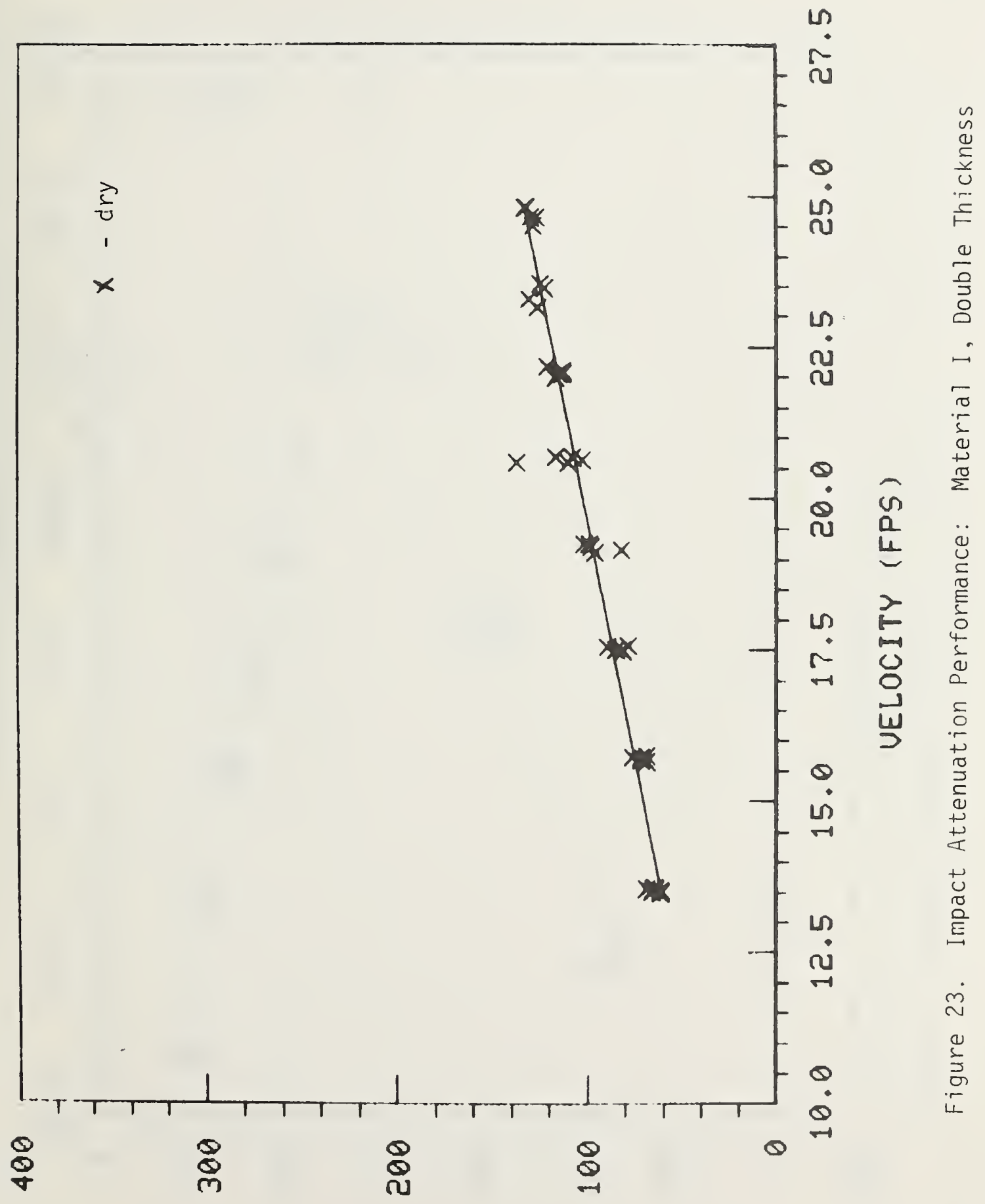

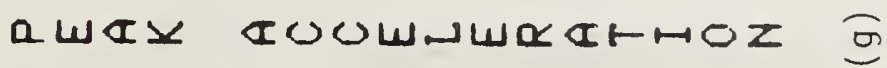




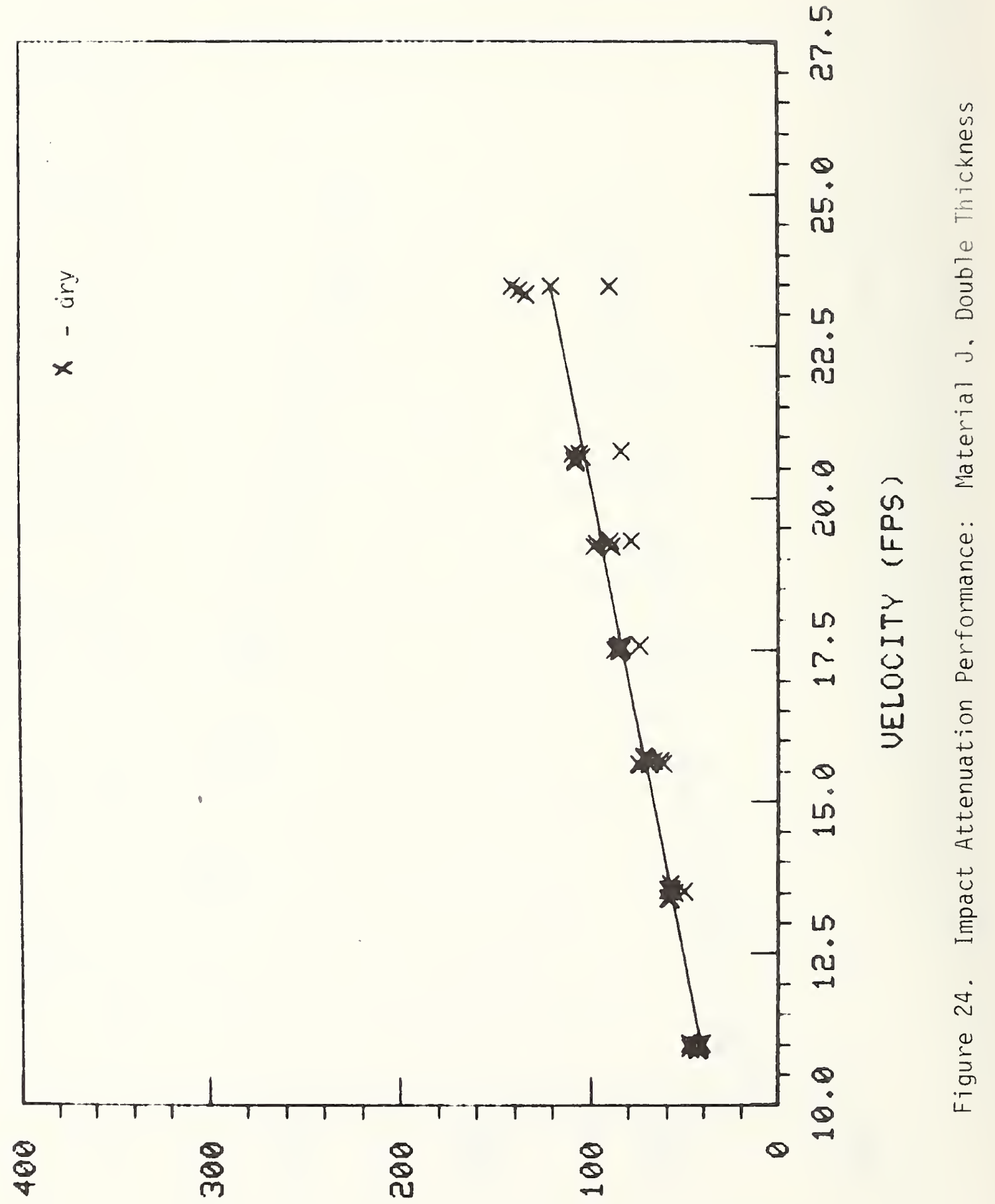

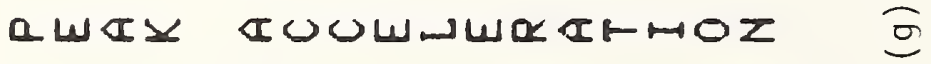




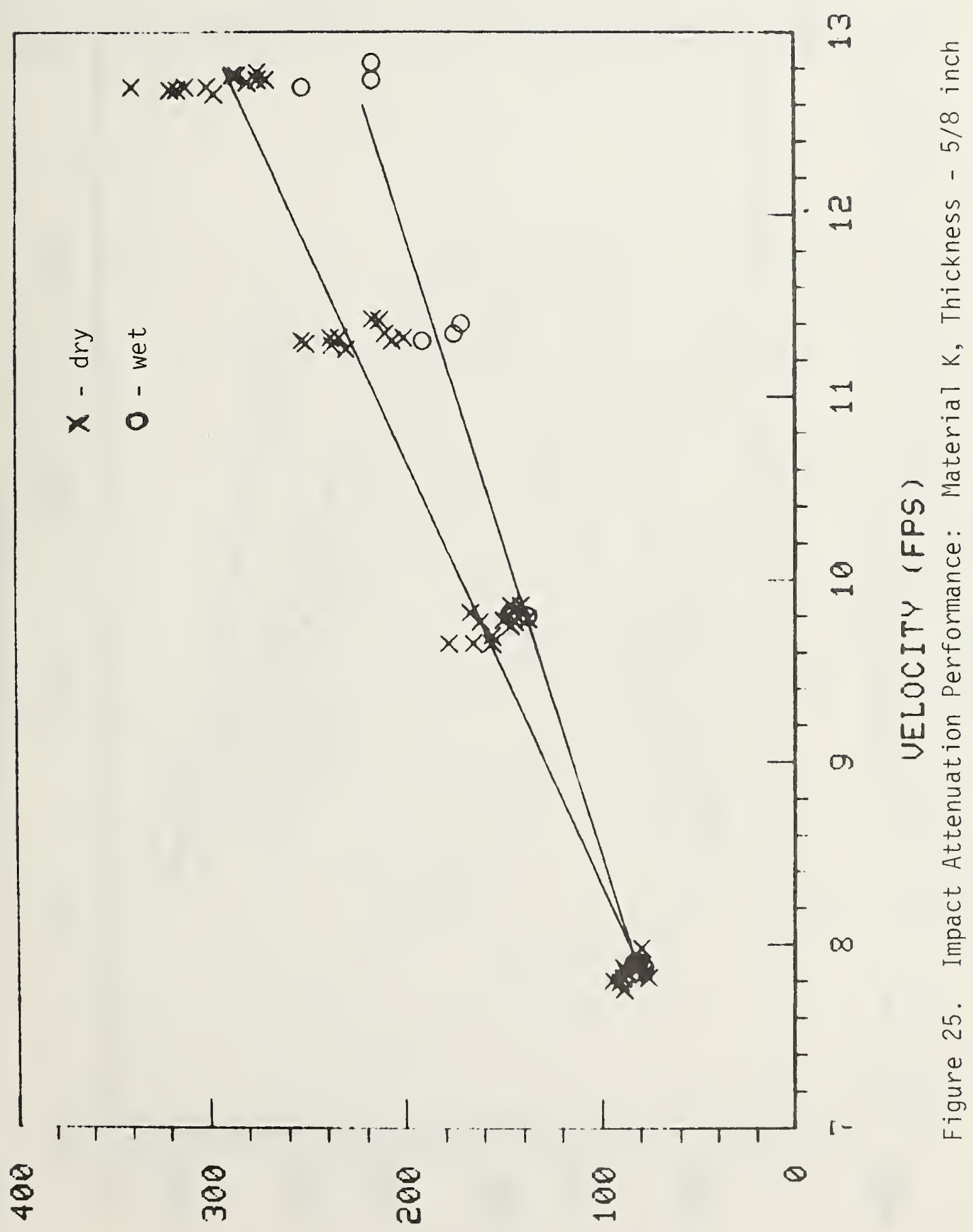

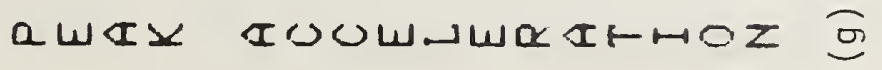




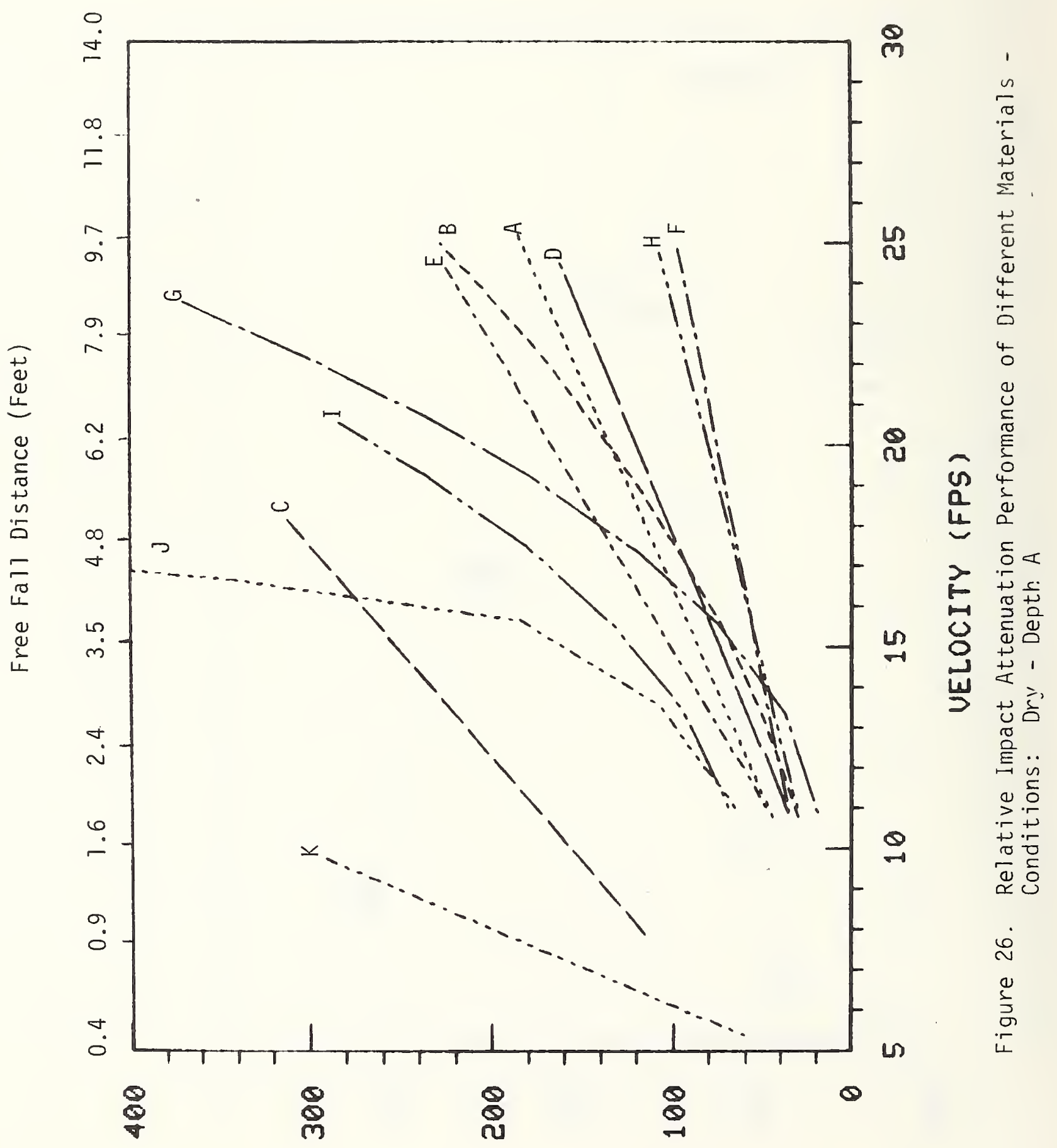

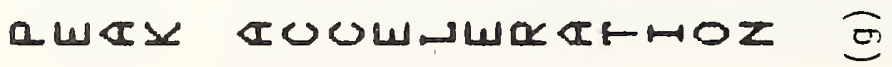




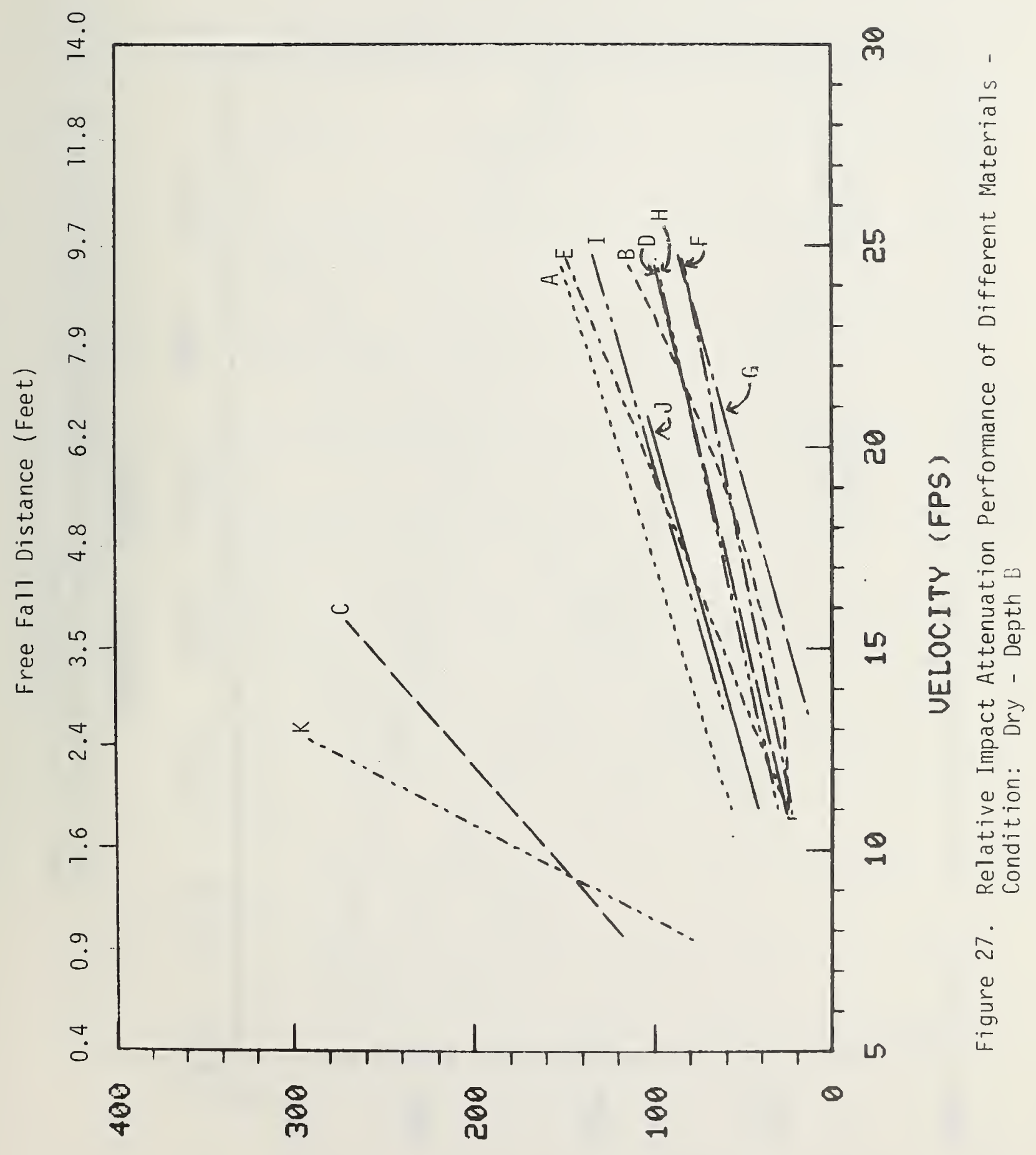

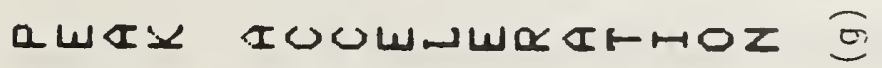




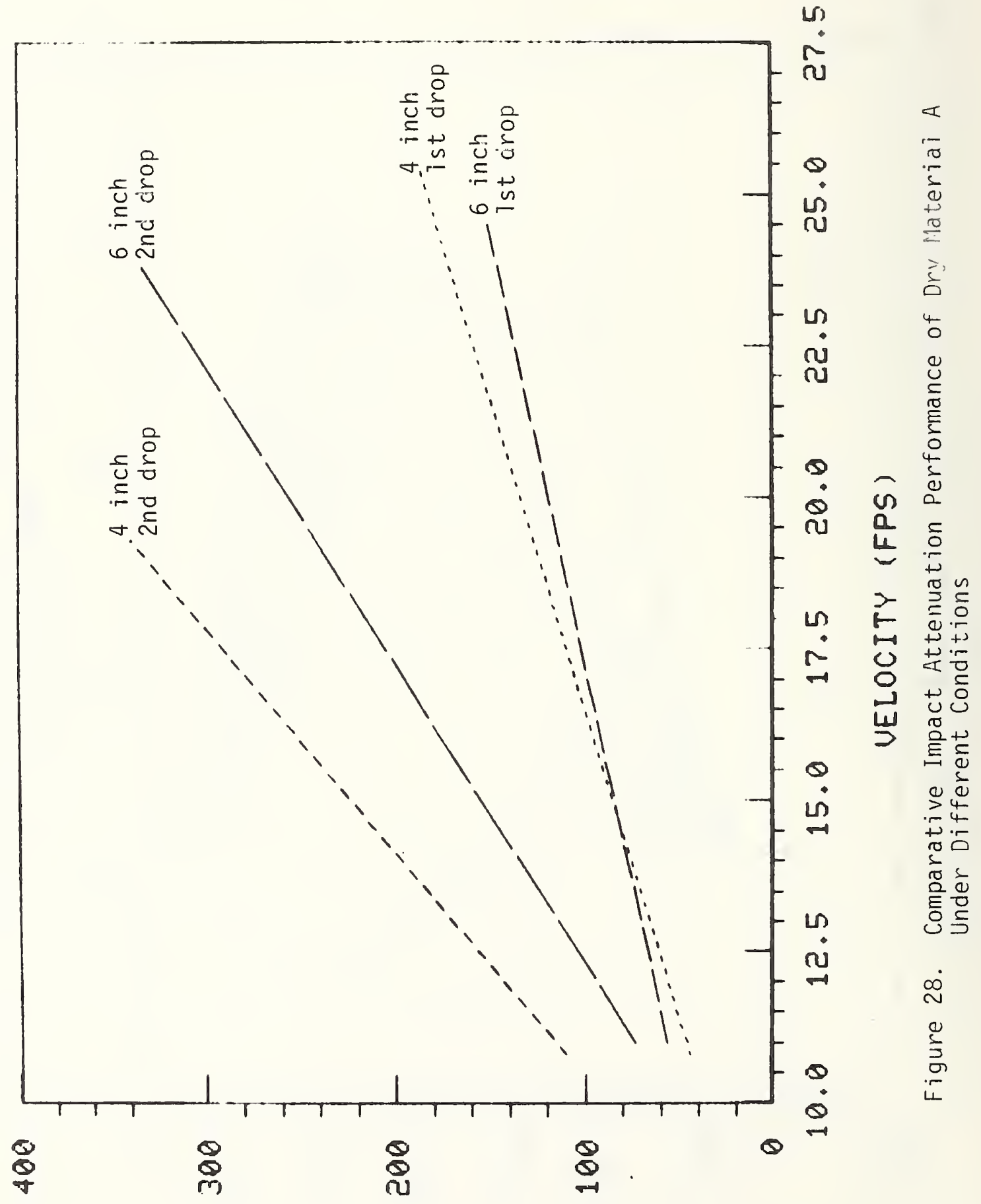

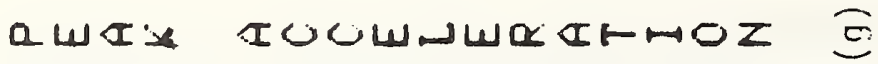




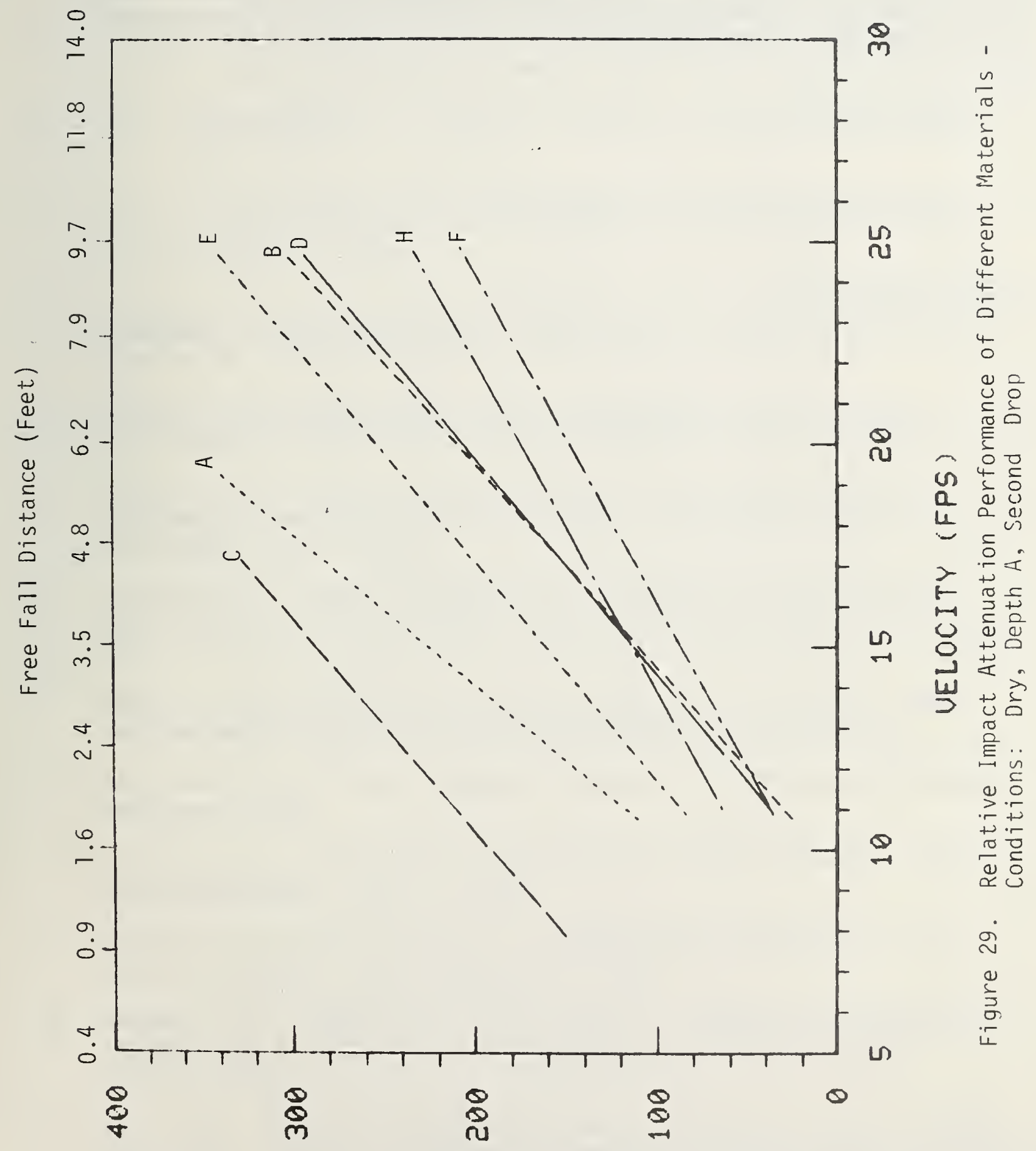

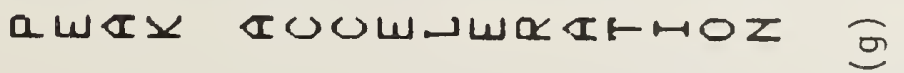




\section{ACKNOWLEDGEMENT}

The authors wish to thank Mr. Raymond G. Russell for his valuable contribution to the experimental phase of this study. The authors also wish to thank Mr. James E. Harris for his contribution to the experimental program, and Ms. Laura Nesbitt for her help in summarizing the data. 


\section{REFERENCES}

1. NRPA, "Proposed Safety Standards for Public Playground Equipmpent and Supporting Rationale," submitted by NRPA to CPSC, May 1976.

2. McConel, W.H. et al., "Product Investigation Report Contract No. FDA73-6, Public Playground Equipment, October 15, 1973.

3. CPSC, "Hazard Analysis of Injuries Relating to Playground Equipment" (NIIC-1201-75-M005), March 1975.

4. Roth, H.P. and Burke, D.M., "Head Impact G in Free Fall on Various Surfaces and Padding Materials," unpublished work submitted by D.M. Burk to CPSC, April 1975.

5. Thomas, L.M., Hodgson, V.R., and Gurdjian, E.S., "Skull Fracture and Management of Open Head Injury," Neurological Surgery, Vol. 2, W.B. Saunders Co., Phila., 1973.

6. Gurdjian, E.S., and Schuwan, H.K., "Management of Skull Fracture Involving the Frontal Sinus," Annals of Surgery, Vol. 95, 1932.

7. Douglass, J.M., Nahrn, A.M., and Roberts, S.B., "Applications of Experimental Head Injury Research," Proc. 12th Stapp Car Crash Conference, S.A.E., 1968.

8. Gurdjian, E.S., "Recent Advances in the Study of the Mechanisms of Impact Injury of Head," reprint from Clinical Neurosurgery, Vol. 19, 1972.

9. Mahajan, B.M., "Standards for Athletic Helmets - A State-of-the-Art and Recommendations," NBS Report No. NBSIR73-276, April 1974.

10. Rowbothan, G.F., "Acute Injuries of the Head," Williams and Williams, Baltimore, 1964.

11. Gurdjian, E.S., "Prevention and Mitigation of Head Injuries," Reprint from Neurosurgery, Vol. 19, 1972.

12. Synder, R.G., "State-of-the-Art: Human Impact Tolerances," S.A.E. Paper No. 700398, 1970, reprinted in 1972.

13. Hodgson, V.R., Thomas, L.M., and Prasad, P., "Testing the Validity of the Severity Index," Proc. of 14th Stapp Car Crash Conference, S.A.E., 1970.

14. Gadd, C.W., "Use of a Weighted-Impulse," Proceeding of 10th Stapp Car Crash Conf., Society of Automotive Engineers, New York, 1966, pp. 164174. 
15. Mohan, D., Bowman, B., Snyder, R.G., and Foust, D.R., "A Biomechanical Analysis of Head Impact Injuries to Children," presented at the Ninth Annual Neuroelectric Society Meeting, December 1977.

16. Berger, R.E. and Calvano, N., "Methodology for Choosing Test Parameters to Evaluate Protective Headgear," NBS Report No. NBSIR781547, November 1978.

17. Draper, N., and Smith, H., Applied Regression Analysis, John Wiley and Sons, New York, NY. 
NBS. $114 A$ (REV. 9.78)

U.S. DEPT. OF COMM.

BIBLIOGRAPHIC DATA

SHEET

4. TITLE AND SUBTITLE

1. PUBLICATION OR REPORT NO.

NBS IR79-1707

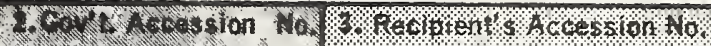

5. Publication Date

IMPACT ATTENUATION PERFORMANCE OF SURFACES INSTALLED UNDER PLAYGROUND FQQUIPMENT

February 1979

8. Performing Organ. Report No.

7. AUTHOR(S)

Bal M. Mahajan and William B. Beine

9. PERFORMING ORGANIZATION NAME AND ADDRESS

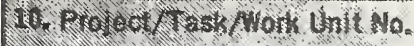

NATIONAL BUREAU OF STANDARDS

DEPARTMENT OF COMMERCE

WASHINGTON, DC 20234

11. Contract/Grant No.

12. SPONSORING ORGANIZATION NAME AND COMPLETE ADDRESS (Street, City, State, ZIP)

Consumer Product Safety Commission

5401 Westbard Avenue

Bethesda, MD 20016

1. So Shsorine Agency Code

13. Type of Report \& Period Covered

15. SUPPLEMENTARY NOTES

Document describes a computer program; SF-185, FIPS Software Summary, is attached.

16. ABSTRACT (A 200-word or less factual summary of most significant information. If document includes a significant bibliography or literature survey, mention it here.)

This report describes a test method and a suggested criterion for evaluating tine impact attenuation performance of playground surfacing materials intended to protect against head injury due to falls. Several types of surfacing materials have been tested and the results are included. These results indicate that some surfacing materials impart peak accelerations below this criterion for fall distances up to 10 feet while others exceed the criterion for relatively short fall distances.

17. KEY WORDS (six to twelve entries; alphabetical order; capitalize only the first letter of the first key word unless a proper name; separated by semicolons)

Playground surfaces; performance; impact; peak acceleration; head injury criterion; test method
18. AVAILABILITY
XXunlimited

For Official Distribution. Do Itot Release to NTIS

[] Order From Sup. of Doc., U.S. Government Printing Office, Wasinington, DC 20402, SD Stock No. SNÓ03-003-

Order From National Technical Information Service (NTIS), Springfield, VA. 22161

\begin{tabular}{|l|l|}
\hline $\begin{array}{l}\text { 19. SECURITY CLASS } \\
\text { (THIS REPORT) }\end{array}$ & $\begin{array}{l}\text { 21. NO. OF } \\
\text { PRINTED PACE. } \\
\text { UNCLASSIFIED }\end{array}$ \\
\hline $\begin{array}{l}\text { 20. SECURITY CLASS } \\
\text { (THIS PAGE) } \\
\text { UNCLASSIFIED }\end{array}$ & 22. PriCe \\
\hline
\end{tabular}


